Gouweloos, J., Dückers, M., Brake, H. te, Kleber, R., Dorgendijk, A. Psychosocial care to affected citizens and communities in case of CBRN incidents: a systematic review.

Environmental International: 2014, 72, 46-65

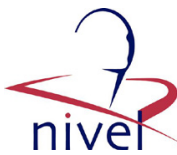

\begin{tabular}{|l|l|}
$\begin{array}{l}\text { Postprint } \\
\text { Version }\end{array}$ & 1.0 \\
\hline Journal website & http://www.sciencedirect.com/science/article/pii/S0160412014000592 \\
\hline Pubmed link & $\underline{\text { http://www.ncbi.nlm.nih.gov/pubmed/24684819 }}$ \\
\hline DOI & $10.1016 /$ j.envint.2014.02.009
\end{tabular}

This is a NIVEL certified Post Print, more info at http://www.nivel.eu

\title{
Psychosocial care to affected citizens and communities in case of CBRN incidents: A systematic review
}

\author{
JuUl GouWeloos ${ }^{\mathrm{A},}$, MiCHEl DÜCKERS $^{\mathrm{A},}$, HANS TE BRAKE ${ }^{\mathrm{A},}$, ROLF KLEBER $^{\mathrm{B}, \mathrm{C}}$, \\ ANNELIEKE DROGENDIJK ${ }^{\mathrm{A}}$ \\ a National Knowledge and Advice Centre for Psychosocial Care Concerning Critical \\ Incidents, Partner in Arq Psychotrauma Expert Group, Nienoord 5, 1112XE Diemen, The \\ Netherlands \\ b Utrecht University, Department of Clinical \& Health Psychology, PO Box 80140, 3508 TC, \\ Utrecht, The Netherlands \\ c Arq Psychotrauma Expert Group, Nienoord 5, 1112XE Diemen, The Netherlands
}

\begin{abstract}
Disasters are associated with a substantial psychosocial burden for affected individuals (including first responders) and communities. Knowledge about how to address these risks and problems is valuable for societies worldwide. Decades of research into post-disaster psychosocial care has resulted in various recommendations and general guidelines. However, as CBRN (chemical, biological, radiological, nuclear) events form a distinctive theme in emergency planning and disaster preparedness, it is important to systematically explore their implications for psychosocial care. The aim of this study is to answer two questions: 1). To what extent does psychosocial care in the case of CBRN events differ from other types of events? 2). How strong is the scientific evidence for the effectiveness of psychosocial care interventions in the context of a CBRN event? A systematic literature review was conducted. Searches were performed in Medline, PsychINFO, Embase and PILOTS. Studies since January 2000 were included and evaluated by independent reviewers. The 39 included studies contain recommendations, primarily based on unsystematic literature reviews, qualitative research and expert opinions. Recommendations address: 1) public risk- and crisis communication, 2) training, education and exercise of responders, 3) support, and 4) psychosocial counselling and care to citizens and responders. Although none of the studies meet the design criteria for effectiveness research, a substantial amount of consensus exists on aspects relevant to CBRN related psychosocial care. Recommendations are similar or complementary to general post-disaster psychosocial care guidelines. Notable differences are the emphasis on risk communication and specific preparation
\end{abstract}


Gouweloos, J., Dückers, M., Brake, H. te, Kleber, R., Dorgendijk, A. Psychosocial care to affected citizens and communities in case of CBRN incidents: a systematic review.

Environmental International: 2014, 72, 46-65

needs. Relevant recurring topics are uncertainty about contamination and health effects, how people will overwhelm health care systems, and the possibility that professionals are less likely to respond. However, the lack of evidence on effectiveness makes it necessary to be careful with recommendations. More evaluation research is absolutely needed.

\section{INTRODUCTION}

Disasters are characterised by their sudden and unpredictable onset, widespread human, material, economic and/or environmental losses and the inability of the affected community or society to cope with it (United Nations, International Strategy for Disaster Reduction). They affect individuals (e.g. children, parents, first responders), specific organisations that have to respond to the disaster (e.g. medical emergency teams, public health organisations, fire brigades) and the community at large. Disasters are associated with a substantial psychological burden for affected people (Bonanno et al., 2010, Neria et al., 2008, Neria et al., 2009, Norris et al., 2002a and Norris et al., 2002b). Although most people are resilient and recover on their own merit, an important minority suffers from long-term mental health disturbances (Bonanno et al., 2010, Grievink et al., 2007, Norris et al., 2002a and Norris et al., 2002b). Psychosocial care aims to address mental health problems and needs. It covers all the support and care directed at the psychological well-being and health of people affected during and after an event targeted at communities as well as individuals. Psychosocial care interventions are needed in the context of disasters or crises, also in case of chemical, biological, radiological or nuclear (CBRN) events. Such events are characterised by the involvement of CBRN agents, such as toxic and hazardous chemicals/materials, chemical and biological warfare agents or radiological materials. Exposure to these agents can be caused by an industrial accident (e.g. 2011 Fukushima Daiichi nuclear disaster, 1986 Chernobyl disaster, 1989 Exxon Valdez Oil spill), warfare (e.g. 1991 Gulf War, 1945 atomic bombings of Hiroshima and Nagasaki, use of mustard gas and tear gas during World War I), or terrorism (e.g. 2001 U.S. Anthrax attacks, 1995 Tokyo Sarin attacks). According to Lemyre et al. (2010b), the psychosocial impacts of CBRN agents are greater than the physical impacts. Recently, the Chernobyl Forum concluded that mental health was the largest public health problem unleashed by the nuclear accident in 1986 (Bromet, 2012). The atypical nature of a CBRN event and its mental health effects justify the question of whether psychosocial care in case of CBRN should be different than after a non-CBRN disaster. This question is even more relevant in a world with a chemical industry that continues to grow by more than 3\% for the continuing 20 years (World Trade Organization, 2012). In 2004, there were 2780 technological related disasters that affected 144 million people (International Federation of the Red Cross and Red Crescent Societies, 2005). Accidents will continue to happen. Combined with the very real threat of criminal activity and malicious intent for the deliberate release of toxic chemicals, a strong and shared approach to deliver customised psychosocial care is called for.

\subsection{Post-disaster psychosocial care: general guidelines and guidance}

Several initiatives have been taken to develop general standards for psychosocial care after disasters to help organisations prepare for and respond to all sorts of disasters, natural as well as technological, accidental or with malicious intent. 
Gouweloos, J., Dückers, M., Brake, H. te, Kleber, R., Dorgendijk, A. Psychosocial care to affected citizens and communities in case of CBRN incidents: a systematic review.

Environmental International: 2014, 72, 46-65

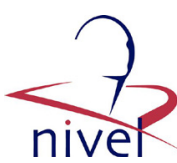

Hobfoll and colleagues synthesised available empirical evidence and formulated five "essential principles" that may be helpful for responders dealing with survivors: promoting a sense of safety, calming, a sense of self- and community efficacy, connectedness and hope (Dückers, 2013 and Hobfoll et al., 2007). In Europe, The European Network for Traumatic Stress (TENTS) developed guidelines that cover a broad spectrum of psychosocial interventions at various moments in time: planning and preparation, initial response (first week), early response (first month) and the response between 1 and 3 months (Bisson et al., 2010). Primary recommendations are summarised in Table 1 . In short, it is recommended that every area should have a multi-agency psychosocial care planning group comprising mental health professionals. Second, responses should aim to promote the five "essential principles" and provide access to social, physical and psychological support. Third, early application of formal psychosocial applications should not occur (for instance "psychological debriefing"), as many early interventions have not been proven to effectively prevent mental health problems. Fourth, trauma focused Cognitive Behavioural Therapy (CBT) is the first line intervention for individuals who suffer from acute stress disorder and acute Post Traumatic Stress Disorder (PTSD). Both disorders are characterised by unwanted intrusive thoughts of the event, avoidance, negative mood alterations and hyperarousal and last less than respectively 1 to 3 months (American Psychiatric Association, 2013). Finally, detailed planning should occur to support local services for several years following the disaster.

\section{[TABLE 1]}

Simultaneously, the EU-project EUTOPA was conducted to create consensus-based guidelines using the Dutch "Multidisciplinary guidelines on early psychosocial interventions after disasters, terrorism and other shocking events" as a point of reference (Impact, 2007 and Te Brake and Dückers, 2013). Overall, a large level of consensus was found among experts and care professionals on the content of the guidelines that cover the first 6 weeks after a disaster. It was concluded that psychosocial interventions in the first period should have the following aims: 1) the promotion of natural recovery and the use of natural resources, 2) the identification of people in need of acute psychological help and 3) the referral and treatment of people who need acute psychological help (for an overview of the recommendations see Te Brake et al., 2009).

The essential principles described by Hobfoll et al. (2007) and the TENTS and EUTOPA guidelines are based on a combination of existing empirical evidence and systematically obtained expert consensus. The strength of scientific evidence for recommendations in these general guidelines varies. The World Health Organization (2013) systematically examined the evidence and rated the strength of some (curative) interventions like CBT for PTSD as "average". They are proven to be effective by multiple Randomised Controlled Trials (RCTs). However, evidence for other recommendations is rated as low. For instance community interventions such as 'population screening for mental health problems shortly after a disaster' or 'providing practical and social support', lack high-quality effectiveness research. It remains uncertain whether and how these interventions should be implemented. Response organisations are in need of guidance, and in spite of a current lack of evidence-based interventions are still expected to provide support during times of crisis. In order to minimise the risk that guidelines reflect untested views of experts, 
Gouweloos, J., Dückers, M., Brake, H. te, Kleber, R., Dorgendijk, A. Psychosocial care to affected citizens and communities in case of CBRN incidents: a systematic review.

Environmental International: 2014, 72, 46-65

guideline development should be based on a combination of empirical evidence and systematically obtained expert consensus (Bisson et al., 2010). The challenge is to identify patterns and at the same time avoid groupthink.

\subsection{Psychosocial consequences of CBRN events}

The general guidelines discussed were developed to help organisations to prepare for and respond to a diversity of calamities and disasters. No distinction is made in disaster characteristics, while a vast body of literature claims that there are definitely reasons to do so. The psychological response to chemical disasters has specific features, which warrant separate discussion (Hall et al., 2002, Hyams et al., 2002 and Weisaeth and Tonnessen, 2003). First, Hyams et al. (2002) concludes after a synthesis of available research that the following features of a health threat are associated with prolonged psychosocial effects: 1) involuntary threats that occur without warning (opposed to individual choice like cigarette smoking); 2) manufactured threats versus natural disasters ("acts of God"); 3) unfamiliar threats with unknown health effects; and 4) threats that pose a danger to children and future generations. All these criteria are applicable to CBRN events. Second, Weisaeth and Tonnessen (2003) conclude that technological disasters have a greater psychosocial impact because they are either caused by malicious intent or human failure, unlike natural disasters, and therefore lead to increased feelings of blame, loss of control, and questions of self-esteem. Third, compared to general disasters, CBRN events typically result in high levels of public fear and uncertainty about exposure to the agent and its negative health effects (Havenaar and Van den Brink, 1997). Fourth, at an organisational level, CBRN disasters typically place a heavy, added burden on the medical system, as a lot of people will have somatic symptoms due to fear of exposure but not because of the hazardous agent. This is illustrated by the 1995 Sarin Attacks in the Tokyo subway: approximately 5510 people sought medical help for physical symptoms even though they were not exposed (Ohbu et al., 1997 and Smithson and Levy, 1999). Also, responders (e.g. fire brigade, police, military, medical personnel, and technologists or toxicologists responsible for decontamination) have to take all kinds of physical self-protection measures to not become contaminated and are concerned about their own health and that of their loved ones (Cowan et al., 2005 and Wynia and Gostin, 2004). In Australian responders, Smith et al., (2011) found that high levels of fear and unfamiliarity may make them less willing to respond to CBRN events compared to events that are more familiar (e.g. bush fires, floods) or less feared (e.g. tsunami, earthquakes). Finally, literature suggests that specific groups of people might be at higher risk for the development of psychosocial problems than after natural disasters. Pregnant women form a risk group because of the impact on the unborn child and increased abortion rates (Auvinen et al., 2001, Bertollini et al., 1990, Knudsen, 1991 and Lemyre et al., 2010a). Children are at risk because they are smaller (lower proximity to the ground) and tend to put things in their mouth which increases the likeliness of exposure to agents (Lemyre et al., 2010a). Evacuees are another risk group. Long-term evacuation due to decontamination procedures has a significant effect on psychological and physical health, as shown after the Chernobyl disaster (Bromet and Havenaar, 2009 and Havenaar et al., 1996). 
Gouweloos, J., Dückers, M., Brake, H. te, Kleber, R., Dorgendijk, A. Psychosocial care to affected citizens and communities in case of CBRN incidents: a systematic review.

\subsection{New contribution}

Despite the presence of generic guidelines on the provision of post-disaster psychosocial care, it is uncertain whether they are applicable to circumstances that involve the (possible) presence of CBRN agents. As these situations might yield the specific psychosocial consequences as mentioned before, a legitimate question is whether these consequences justify different psychosocial interventions to deliver optimal care to people exposed to CBRN disasters. What do we know about psychosocial care after CBRN events and to what extent does it depart from the general guidelines? And if there are differences, what are the implications for actors at different positions within the psychosocial care delivery system? To our knowledge, this is the first study that systematically reviews the international literature in order to examine this question. This study aims to answer two questions: $1)$.

To what extent does psychosocial care in the case of CBRN events differ from other types of events?

2).

How strong is the scientific evidence for the effectiveness of psychosocial care interventions in the context of a CBRN event?

The first question will result in an overview of recommendations on behalf of an optimal psychosocial care to communities, organisations and individuals confronted with CBRN-events. The second question will contribute to the knowledge about the evidence base of psychosocial care and the identification of possible gaps in research.

\section{METHODS}

\subsection{Databases}

To identify empirical studies, electronic searches were performed in Medline, PsycINFO, EMBASE and PILOTS. Searches were conducted in February 2013 and January 2014.

\subsection{Search strategy}

The search strategy was based on a combination of search terms related to CBRN events together with Psychosocial interventions/approaches (see Table 2 for the Medline search strategy). Terms were used in keyword, title, abstract and singular and plural form, with medical subject headings (MeSH) if the database supported this option.

\section{[TABLE 2]}

\subsection{Inclusion and exclusion criteria}

Studies were excluded if the setting was not a CBRN event. Second, studies were excluded if no psychosocial intervention or approach was described that was specifically related to prevention, detection, mitigating or amelioration of the psychosocial impact. Studies not published in English and published before the year 2000 were excluded as well. No exclusion criterion was applied in relation to the target population: studies on civilians, specific groups of civilians (such as children or elderly), responders and communities were included. 
Gouweloos, J., Dückers, M., Brake, H. te, Kleber, R., Dorgendijk, A. Psychosocial care to affected citizens and communities in case of CBRN incidents: a systematic review.

Environmental International: 2014, 72, 46-65

To answer the second research question on the effectiveness of interventions, additional stringent inclusion criteria were adopted concerning the study design. We focused on systematic reviews, randomised controlled trials (RCTs), controlledbefore-and-after studies (CBAs), interrupted time series (ITSs) and uncontrolledbefore-and-after studies (UBAs; the weakest design).

\subsection{Screening}

Screening took place in different stages. During the first round, four reviewers independently screened articles retrieved on title and abstract or, if needed, the full text, based on the inclusion criteria related to setting (CBRN events), psychosocial intervention and population (community/responder/individuals). One reviewer screened all the articles (JG). The other three reviewers each screened an equal number of articles. In those instances in which discrepancies were found, an independent reviewer was consulted to decide if the study should be included for the first round.

During the second round, the quality of the study design was examined. Data were extracted using restructured forms by 1 reviewer (JG). The data extraction was checked for completeness and correctness by an independent second reviewer (MD). In the case of systematic reviews, the topic, setting, search period, data sources, number of included studies, main outcomes, and conclusions were described. For non-review articles, the study setting and the nature of the intervention were described.

For the second research question, a general hierarchy of evidence classification was applied, the first being the strongest: systematic reviews, RCTs, CBAs, ITSs, and UBAs. For all included articles, the strategy was to report an indication of the methodological quality of the study. This approach was based on Cochrane Effective Practice and Organisation of Care Group (EPOC) criteria for reviews, RCTs, CBAs and ITSs (The Cochrane Collaboration; criteria are summarised in Appendix A). We chose these criteria because the research focus of the EPOC Group is on interventions designed to improve the delivery, practice, and organisation of health care interventions. Classification on methodological quality was based on the rule that: If zero to two of the criteria are not fulfilled or reported as unclear in the case of a RCT, CBA, or ITS, the study can be considered "strong". Study designs with half or less of the criteria not fulfilled or reported unclearly can be labelled "moderate". Designs are considered "weak" if more than half of the criteria are not fulfilled or reported. UBAs are "inherently weak due to the absence of a comparison group and the data to examine trends (Eccles et al., 2003)."

\subsection{Categorisation of findings}

To answer research question 1 in a structured manner, we adopted the psychosocial risk assessment and management (P-Ram) framework for CBRN events to categorise recommendations found in the literature (Lemyre et al., 2005). This categorization framework was needed to enable a clear overview of the recommendations. We selected this comprehensive framework, because it does not recommend specific interventions, but divides them into 4 categories: risk communication, education, social support and professional counselling. To fit all the studies found, we broadened the categories and changed them into 1) risk- and crisis communication (communication during a crisis entails more than communication about risks), 2) education, training and exercise (broader than education), 3) support (includes 
Gouweloos, J., Dückers, M., Brake, H. te, Kleber, R., Dorgendijk, A. Psychosocial care to affected citizens and communities in case of CBRN incidents: a systematic review.

Environmental International: 2014, 72, 46-65

practical support and a variety of information) and 4) professional care and counselling (covering specialised treatment).

\section{RESULTS}

\subsection{Studies included}

A total of 2252 studies were found in the various literature databases. Approximately $42 \%$ of these were provided by Medline. After the total number of studies was checked for duplicates, the abstracts of 1966 unique studies were examined using the inclusion criteria. After abstract screening and full text confirmation (first round screening), 58 articles were found to be eligible. Two reviewers assessed these articles in full text. This excluded another 19 studies as further analysis showed that they did not describe a psychosocial intervention or CBRN event. As a result, 39 studies were included to answer research question 1. In Section 3.3 we describe how useful these studies are for answering research question 2. Appendix B provides an overview of these 39 studies and describes their design, the targeted CBRN event(s), the target group of the intervention (community, organisation or individuals), the proposed intervention(s), and executors of the intervention (e.g. authorities or mental health personnel).

\subsection{Research question 1. CBRN related differences}

\subsubsection{Type of CBRN event}

Most of the 39 studies aim to describe psychosocial responses after CBRN events caused by a malicious intent ( 31 studies), such as terrorism or war, 3 studies focus solely on technological, man-made disasters (accidental or due to negligence) in which CBRN agents were released and 5 studies make no distinction between the two. Almost all included studies base their recommendations on the literature of multiple CBRN events or disasters, most commonly the 2001 U.S. anthrax attacks, 1995 Tokyo Sarin attacks, 1986 Chernobyl disaster, Gulf War (1990-1991), 2011 Fukushima earthquake disaster that damaged a nuclear power plant, and the 1987 Goiana, Brazil radiation accident. The authors often are inspired by literature on nonCBRN events, such as 9-11 World Trade Center attacks in 2001, 2005 London bombings, 1995 Oklahoma City bombings, 2003 SARS pandemic, and 1979 Three Miles Island accident. Moreover, concerning the type of CBRN event (e.g. terrorist attack and accident), most of the unsystematic literature reviews and expert opinions do not base their recommendation solely on studies describing the type of event focused on. For instance, a study on bioterrorism can also include information from studies on the psychosocial consequences of $9 / 11$ or Chernobyl.

\subsubsection{Psychosocial care}

To provide a clear overview of the various recommendations of the 39 studies, we categorised them into 1) risk- and crisis communication, 2) education, training and exercise, 3) support and 4) professional care and counselling.

\subsubsection{Risk- and crisis communication}

Conflicting or unclear messages from authorities and experts are considered to enhance uncertainty and worry among the public and may increase psychosocial problems and risky behaviour, such as non-adherence to prophylactic medication or ignoring advice to evacuate (Lemyre et al., 2010b, Rubin et al., 2012 and Wessely, 2005). Unclear information potentially increases the amount of people seeking help, although not suffering from medical problems due to exposure to the CBRN incident 
(Hick et al., 2011). A large majority of the studies (29; Appendix B) underlines the importance of clear and consistent risk- and crisis communication from governmental and (public) health organisations. Recommendations can be divided into the kind of information that must be provided and how this information must be communicated.

Regarding the kind of information, authors advise authorities to communicate about risk of exposure, objective signs of exposure rather than subjective (e.g. location or fever instead of increased heart rate, or other physical symptoms also caused by anxiety), protective behaviour (e.g. adherence to advice to wear protective clothing), dangerous behaviour (e.g. searching for loved ones in a high radiation area), quarantine and isolation, decontamination strategies, vaccination strategies and distribution of medication ( Dodgen et al., 2011, Hall et al., 2004, Rubin et al., 2012, Sheppard et al., 2006 and Ursano et al., 2002).

To make sure this information reaches the public (how), a vast amount of recommendations deals with actions authorities should take before, during, and shortly after an event and, in the long term ( Ritchie et al., 2004). Before an event, it is advised first to prepare a strong and proactive risk communication strategy that integrates public risk perspectives ( Hall et al., 2004, Lemyre et al., 2010b, Noy, 2004, Oordt, 2006 and Rubin et al., 2012 Tinker and Vaughan, 2004 and Wodarski, 2004). Second, pre-event communication on CBRN agents helps people to make well-informed judgements rather than adopting spontaneous precautionary actions that may not produce optimal health outcomes ( Pastel and Ritchie, 2006 and Sheppard et al., 2006). It takes out the mystery of microorganisms and enhances a sense of self-efficacy, mastery, shared expectations and preparedness ( Fullerton et al., 2004 and Lemyre et al., 2010b). However, Rubin et al. (2012) warn that it is difficult to find a naturally occurring moment that people become receptive to pre-event information. Providing information too early will cause people to be less receptive because the occurrence and consequences of a CBRN attack are too unlikely, while providing it too late means that people are already feeling uncertain and threatened for some time, maybe more than necessary. Furthermore, Durodie (2004) concludes that preparing the public for CBRN attacks cannot be shortcircuited by a "technical" information campaign. Public resiliency to the mass chaos, fear and conflict which bioterrorism aims to generate benefits from a sense of common purpose and active political engagement in society.

During or shortly after the event, the following recommendations are made (Alexander and Klein, 2003, Blanchard et al., 2005, Cwikel et al., 2002, Hyams et al., 2002, Lemyre et al., 2010a, Lemyre et al., 2010b, Pastel and Ritchie, 2006, Ursano et al., 2002 and Wessely, 2005):

Set up a central information centre.

Work closely with community members and leaders.

Develop a collaborative relationship with the media and provide them with good quality information to avoid rumours or false information that may enhance uncertainty.

Organise credible governmental leaders for the media who have a basic understanding of CBRN agents, health effects and other scientific issues. Utilise popular news media.

Give consistent messages to different groups in the community (e.g. do not raise suspicion of discrimination, as illustrated by the 2001 U.S. Anthrax attacks in which 
Gouweloos, J., Dückers, M., Brake, H. te, Kleber, R., Dorgendijk, A. Psychosocial care to affected citizens and communities in case of CBRN incidents: a systematic review.

Environmental International: 2014, 72, 46-65

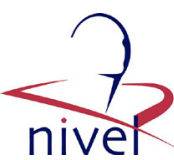

the predominantly African American postal workers believed that unfair treatment on the basis of race/ethnicity and socioeconomic status had occurred).

Long-term surveillance studies should be initiated to generate evidence-based answers to questions about rates of exposures and diseases (Hyams et al., 2002, Ursano et al., 2002, Wessely, 2005 and Wodarski, 2004). This research should be set up in an early stage after an incident or disaster and not in response to later public/media pressure and can play an important role in preventing or mitigating social stigma and diminishing concerns about (mental and physical) health effects and reproductive behaviour (Lemyre et al., 2010a and Ursano et al., 2002).

\subsubsection{Education, training and exercise}

27 studies focus on preparation of the health care system and training of responders who take care of the affected community and high risk groups. The health care system has an essential role: a confronted community needs both emergency intervention and long-term health care. During and shortly after a CBRN event, the medical system might be confronted with a large group of people suffering from CBRN related problems that might be caused by physical exposure, but may be very well caused by fear of exposure. This happened, for instance, after the Tokyo Sarin attacks in 2005 and the radiological contamination incident in Goiania, Brazil, in 1987 (Knudson, 2001 and Petterson, 1988). To prevent the health care system from getting overwhelmed, and to provide optimal short- and long-term psychosocial care for those affected, the following recommendations are made (Becker, 2005, Benedek et al., 2002, Fullerton et al., 2004, Hall et al., 2002, Markel et al., 2008, Noy, 2004, Pastel and Ritchie, 2006, Scharoun and Dziegielewski, 2010, Ursano et al., 2002, Wessely, 2005 and Wodarski, 2004):

- Plan and train for a quick mobilisation of the system to be able to quickly diagnose symptoms of contamination and provide treatment.

- Develop and coordinate a(n electronic) network for quick information dissemination between different organisations (medical system, first responders, public health organisations, authorities, etc.).

- Prepare for decontamination and quarantine measures.

- Implement a triage system that helps to distinguish those with medical problems from those with symptoms due to fear of exposure. To accomplish this, the mental health care system must join with the public health system and emergency response system.

- Train in signalling and responding to psychological problems after disasters, such as fear, anger, and somatic symptoms.

- Prepare for follow-up and registries, that are needed in the long term to identify those with psychical injuries such as late radiation induced damage or cancer, or psychiatric disorders. Monitoring these medical health consequences of CBRN agents will require expert input from epidemiologists.

High risk groups require specific preparation. Lemyre et al. (2010a) warns first responders to be prepared for psychosocial interventions for children. Drug treatment needs to be modified for children's lower body mass, decontamination units must be customised to child size, and evacuation procedures are to be made responsive to the fear of children to be disconnected from their family. Evacuees who are permanently displaced pose significant problems with the continuity of their complex medical and social care (Hick et al., 2011). Also, elderly people may need more preparation time 
Gouweloos, J., Dückers, M., Brake, H. te, Kleber, R., Dorgendijk, A. Psychosocial care to affected citizens and communities in case of CBRN incidents: a systematic review.

Environmental International: 2014, 72, 46-65

because they are more difficult to evacuate and may react differently to medication (Johnson et al., 2006). Furthermore, after the Japanese earthquake in 2011 that damaged a nuclear power plant in Fukushima, midwives advised pregnant women about radiation effects to relieve their worries about the negative impact upon their unborn child (Kikuchi and Kikuchi, 2012).

Responders and medical staff should also educate and train themselves in the (health) effects of CBRN agents and in using protective measures to be able to respond appropriately when disaster strikes. Focus groups among nurses reveal that in order to support nurses' ability to cope during bioterrorism, education on CBRN agents, decontamination procedures, self-protection measures, available content experts, information on ways to communicate with their family and training with scenarios using protective equipment are important interventions that may reduce their anxiety to respond (O'Boyle et al., 2006). From previous incidents, such as the SARS epidemic, we know that concerns about contamination of responders themselves or their loved ones, may make them less willing to come to work (Alexander and Klein, 2003, O'Boyle et al., 2006 and Williams and Williams, 2010). Another factor that may complicate the response to CBRN events is the need for responders to wear protective equipment. This can cause anxiety or claustrophobia which may be reduced by frequent practice to become accustomed to the experience of functioning when wearing protective gear (Alexander and Klein, 2003, Oordt, 2006 and Pastel and Ritchie, 2006). Responders who suffer from severe gas mask phobia may benefit from a combination of exposure therapy and relaxation techniques (Oordt, 2006). Finally, to strengthen resilience among responders and authorities, it is strongly recommended to learn about personal reactions to stress and stress management techniques (Alexander and Klein, 2003, Reid et al., 2005, Ursano et al., 2002 and Vazquez et al., 2010).

3.2.2.3. Support Interventions following a CBRN event should be practical and supportive: "The first thing people want is practical support, the second thing is to talk or not or talk with people from their own social network; professionals come low down on the list" (Wessely, 2005). 15 studies addressed the importance of the accessibility of support for the affected community (Dodgen et al., 2011, Hick et al., 2011, Lemyre et al., 2010a, Lemyre et al., 2010b, Oordt, 2006 and Ritchie et al., 2004) and specific groups such as children and responders (Benedek et al., 2002, Kikuchi and Kikuchi, 2012, Lemyre et al., 2010a, O'Boyle et al., 2006, Ursano et al., 2002 and Vazquez et al., 2010). Various recommendations to facilitate support are given. At first, family reunification is a priority and a family reunification system will need to be activated and aggressively implemented (Hick et al., 2011). Second, in case of a (CBRN) terrorist attack, authorities may wish to block mobile phones. Because people become more anxious and less resilient when they cannot reach their loves ones, they should be reluctant to implement this measure and search for ways to keep such a blockage as short as possible (Wessely, 2005). Third, practical support to return to a state of normalcy with respect to appropriate permanent housing, schooling and community service is essential to reduce the risk of long-term psychological impact on children and families (Lemyre et al., 2010a). Fourth, attention must be given to the fact that first responders are often also parents whose primary concern is with their family. Organisations should facilitate communication with family members of their workers and provide safety to their family; otherwise it will be difficult for 
responders to keep doing their work for they may fear contaminating their family and stay home (Lemyre et al., 2010a and O'Boyle et al., 2006). According to Benedek et al. (2002), "it is unrealistic to expect staff to respond with empathy for their patients if their own emotional needs are ignored". Finally, in case of CBRN disasters, responders should be aware that quarantine makes social support inaccessible and thereby may lead to psychosocial problems (Lemyre et al., 2010a).

3.2.2.4. Professional care and counselling

18 studies recommend specific psychological interventions for people with or at risk of mental health problems. In line with the general recommendations on post-disaster psychosocial care, it is advised to (Benedek et al., 2002, DiGiovanni, 2003, Dodgen et al., 2011, Fullerton et al., 2004, Hyams et al., 2002 and Ursano et al., 2002Wessely, 2005)

- Identify those at risk of adverse mental health problems and monitor vulnerable groups.

- Offer CBT to those suffering from psychiatric problems and avoid early interventions such as immediate grief counselling or psychological debriefing, as they may not be effective.

Recommendations on professional care, specific to CBRN disasters and not typically recommended after other disasters are:

- Reassure people who are in fear of contamination but are not actually contaminated, it is advised to medically screen them or offer them prophylactic medication (Benedek et al., 2002 and Lemyre et al., 2010b).

- Make information cards, available via hospitals, with information on likely emotional reactions and how people can manage these themselves. This may be helpful for a large group of citizens who will come to hospitals because they experience physical symptoms while they have not been exposed (Wessely, 2005).

- Implement a programme to identify, monitor and treat people suffering from idiopathic symptoms (Engel et al., 2004, Engel et al., 2006 and Engel et al., 2007).

Engel developed a programme based on the literature on the 1991 Gulf War (after which $17 \%$ of UK Gulf War veterans suffered from the 'Gulf War syndrome' and suffered from symptoms of chronic pain, fatigue and depression) comprising preventive efforts, such as family education and support networks, signalling those with symptoms, low intensity primary care treatment, and finally, intensive rehabilitation to reduce morbidity. Finally after Fukushima, various interventions to prevent PTSD among children have been conducted (but not evaluated), such as setting up play centres for children in evacuation centres (Kikuchi and Kikuchi, 2012).

\subsection{Research question 2. Effectiveness of interventions}

To answer the second research question on effectiveness of interventions, we evaluated the design of the 39 studies. Appendix B provides a description of the design. Most studies are unsystematic literature reviews (21 studies). 9 studies are expert opinions (often in combination with unsystematic literature reviews), guidelines (2), or are a description of an intervention or scenario (2). None of these studies clearly specify their research design, provide a clear account of the process by which their findings are produced or describe their method of analysis to support the interpretations and conclusions. We found 3 qualitative studies (using focus 
Gouweloos, J., Dückers, M., Brake, H. te, Kleber, R., Dorgendijk, A. Psychosocial care to affected citizens and communities in case of CBRN incidents: a systematic review.

Environmental International: 2014, 72, 46-65

groups or open-ended questionnaires) and 1 cross-sectional survey that did provide a description of their research methods. However, none of the 38 studies described above are systematic reviews, RCTs, CBAs, ITSs or UBAs and do not meet the EPOC design criteria. Therefore quality of design is rated as "weak". We found 1 systematic review (Rubin et al., 2012). The quality of this study is rated as weak because more than half of the criteria for reviews (Appendix A) are not fulfilled or reported. As a result, none of these 39 studies can be included to ascertain the effectiveness of psychosocial interventions.

\section{DisCUSSION}

The potential psychosocial impact of CBRN events in combination with the question of whether an alternative response and aftercare is appropriate inspired us to conduct the current study. The studies examined illustrate that (the risk of) CBRN agents in a disaster or emergency situation have specific effects on physical, mental, behavioural and social health.

\subsection{Research question 1. CBRN related differences}

To what extent does psychosocial care in case of CBRN events differ from other types of events? While going through the 39 studies based primarily on expert consensus, qualitative interviews and unsystematic literature reviews, we reached qualitative saturation. Based on the collected material, we can conclude that most of the recommended psychosocial interventions are in line with or complementary to general guidelines on post-disaster psychosocial care. The primary recommendations of the general TENTS (Table 1) and EUTOPA guidelines appear applicable to CBRN events. This is the case with process measures: forming multiagency-planning groups, developing and testing of psychosocial care plans, education and training of responders. In the light of the care content, the starting premise of psychosocial care is identical: most affected people are resilient, efforts must be made to provide practical and social support, a minority will develop long-term psychosocial problems demanding monitoring activities especially of high risk groups (children, elderly, people with previous mental disorders and ethnic minorities), and timely treatment must be available for those in need.

The compatibility of process measures and care characteristics can be attributed to similarities in risk factors and psychosocial problems. Many of the risk factors that need to be reckoned with when delivering psychosocial care are not different in case of a CBRN event: e.g. severity of traumatic exposure, previous mental health problems, death of loved ones, injury to self or family members, female gender, lower socioeconomic status, smoking, ethnicity and evacuation (Bonanno et al., 2010, Dodgen et al., 2011 and Neria et al., 2009). Still, as pointed out in the introduction and in many of the included studies, there seems to be an essential difference urging for additional interventions in case of CBRN disasters. Two themes are elaborated upon in the literature particularly: risk communication and specific preparation needs of the health care system. These themes are found respectively on the community- and organisational level of the psychosocial care delivery system. Risk communication is essential to decrease uncertainty about contamination and decontamination effects. A reassuring thought, in line with other disaster studies, is that the included studies encourage putting panic reactions of the public into perspective. From the 2005 London bombings, 9/11, 2001 Anthrax attacks and 1995 Sarin attacks we can learn that the public does not seem prone to panic directly after 
Gouweloos, J., Dückers, M., Brake, H. te, Kleber, R., Dorgendijk, A. Psychosocial care to affected citizens and communities in case of CBRN incidents: a systematic review.

Environmental International: 2014, 72, 46-65

a disaster and tends to behave appropriately (Sheppard et al., 2006). Still, this does not take away the difficult responsibility to deliver clear and consistent messages in the context of a CBRN disaster. What complicates matters is that lay persons and experts often disagree about the health risks from any given toxic source such as radiation or toxic materials: experts tend to base their opinions on statistics, while the non-scientific people are likely to formulate their risk assessment on personal experience, shared stories or sensationalist media sources and tend to think of all toxic substances as one group (Cwikel et al., 2002).

Specific preparation needs are necessary given the major assignment responders and health care providers are confronted with in the wake of a CBRN event. A particularly difficult task is to differentiate between physical consequences of exposure to CBRN agents and effects of stress. Furthermore, when treating people, responders must also take care of their own health in order to not get contaminated. Especially in situations with high uncertainty about health risks, training and preparation efforts must be directed at minimising or mitigating psychosocial problems among responders and stimulate feelings of control and mastery (Considine and Mitchell, 2009 and Rokach et al., 2010). Some studies indicate that responders are at less risk of adverse mental health outcomes, probably because they can cope better due to training and have a specific role and task during a disaster (Norris et al., 2002a, Norris et al., 2002b and Weisaeth and Tonnessen, 2003). Having a role gives control over the situation and meaning to it, as compared to a civilian who might feel more passively overwhelmed by the disaster not knowing what to do or what happened to him/her. However, not all responders have received specific CBRN training or have any experience. This may explain why they might feel less certain of their performance and may be more afraid of making mistakes in case of a rare event like a CBRN event (Smith et al., 2011). Therefore, it is important to distinguish between responders with specific CBRN training/experience and those with less training/experience who are none-the-less expected to respond.

Although studies show that public communication and education and preparation of responders are normal elements of the "disaster cycle" (Alexander, 2002), in the 39 studies they receive a substantial amount of attention, even more than "traditional" individual psychosocial interventions such as support and professional care and counselling. Authors describe these latter interventions as important, but do not elaborate on them and their recommendations depend heavily on the general disaster and mental health literature. Otherwise, the general psychosocial care guidelines take the specific CBRN-related psychosocial consequences into account less. The psychosocial risk assessment and management (P-RAM) framework for CBRN events of Lemyre et al. (2005) can serve as a tool to integrate the current guidelines with the knowledge of CBRN events. The framework is based on and in line with general disaster frameworks (reference is made to the handbook by NSW Institute of Psychiatry and Centre for Mental Health, 2000), but the framework also gives attention to the risk communication and takes the specific role of the health care system and medical personnel into account. Although we highly recommend combining this framework with psychosocial care guidelines, we also advise being aware that guideline implementation will be just as challenging for CBRN events as it is for other disasters. The implementation of guidelines is a crucial step in disaster preparation. And it is a problematic step. The field of post-disaster psychosocial care 
Gouweloos, J., Dückers, M., Brake, H. te, Kleber, R., Dorgendijk, A. Psychosocial care to affected citizens and communities in case of CBRN incidents: a systematic review.

Environmental International: 2014, 72, 46-65

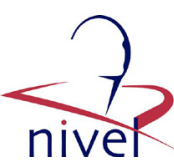

displays a gap between guidelines developed by experts and actual field practice (Te Brake and Dückers, 2013 and Witteveen et al., 2012).

To put it shortly, in relation to the first research question, we conclude that recommendations found in the studies are similar or complementary to general postdisaster psychosocial care guidelines with a notable emphasis on risk- and crisis communication and specific preparation needs. Second, although predominantly focussing on the community and organisations, psychosocial interventions in the case of a CBRN event are ultimately aimed at protecting and supporting individuals risk and crisis communication, education, training and exercise, support, and psychological care and counselling. Yet the community is used as mediating or moderating factor and as a vehicle to reach individuals. Efforts invested in risk communication (prevent or reduce anxiety, fear or unrest) and system preparedness (well-equipped and knowledgeable professionals) are undeniably valuable for the health and wellbeing of individuals - both citizens and professionals. Third, responders, although some may be more resilient than citizens due to training, selection and role behaviour, are just as worried about the fate of their families, friends and personal well-being. Responders will perform a crucial job for the individuals and communities affected by CBRN events. While doings so, they can be exposed to agents that can be mitigated by wearing protective gear or operating in isolation; measures that are paradoxically stressful themselves.

Finally, when interpreting these results, it is important to realise that they are heavily based on unsystematic literature reviews. Many studies are non-empirical and subjective. Moreover, this implies that, for a large part, this review does not include original data. The recommendations listed are based on behavioural, social and psychological consequences of CBRN events (often prevalence studies or unsystematic literature reviews themselves), reflect the author's estimation of how to decrease the risk of these negative consequences, and are not based on evaluations of interventions. Another limitation to be aware of is that a substantial portion of the recommendations are based on knowledge of regular psychological- and psychiatric literature, as well as crisis management studies that are extrapolated to the CBRN domain (e.g. Benedek et al., 2002, Lemyre et al., 2005, Lemyre et al., 2010a and Lemyre et al., 2010b). Extrapolation also occurs the other way around: Reid et al. (2005) discussed the application of a bioterrorism training in response to flooding. Furthermore, a lot of the studies discuss many different disasters, CBRN as well as terrorism and in some cases even natural disasters. Many disasters appear in more than one of the studies. This raises the risk that authors are encouraged to focus on similarities and less on context-specific idiosyncrasies.

\subsection{Research question 2. Effectiveness of interventions}

The second study objective was to determine if there is any scientific evidence for the effectiveness of psychosocial interventions after CBRN events. After reviewing more than 1900 articles, no studies were found that provide methodologically sound evidence to confirm the effectiveness of recommended interventions. We planned to apply strict inclusion criteria on study design to be able to conclude something about the effectiveness of interventions. UBAs, studies without controls and only before and after measurements, are technically insufficient to attribute effects to a given phenomenon or intervention (Eccles et al., 2003). But even UBAs were not found. How can it be explained that we did not find any effectiveness studies into psychosocial care after CBRN events? One reason can be that only studies after the 
Gouweloos, J., Dückers, M., Brake, H. te, Kleber, R., Dorgendijk, A. Psychosocial care to affected citizens and communities in case of CBRN incidents: a systematic review.

Environmental International: 2014, 72, 46-65

year 2000 were included in this review. Major disasters such as Chernobyl and Bhopal happened in the previous century. However, the literature we studied frequently referred to studies published before the year 2000 and we found no referral to evidence-based interventions. The Great Japan Earthquake is too recent to determine its effects and the effectiveness of interventions. Another reason may be that focus of CBRN studies has been on the prevalence of health problems and not on prevention, mitigation and amelioration of these problems. Effectiveness of psychosocial care remains difficult to assess. Many psychosocial interventions after CBRN events are broad-scale community interventions, such as risk communication, family and community support, and primary and secondary preventions that do not follow a strict protocol and seek to reach a large group of people with variation in stress reactions, level of exposure, past experiences, etc. Therefore, the preferred circumstances for RCTs (in general the ultimate design for effectiveness studies) are more difficult to obtain. On the other hand, less strict designs may yield better insight into treatment effects, for example, because they allow evaluation of treatments that are actually delivered in the field and sample without obvious bias to those enrolling which improves ecological validity (Seligman, 1995). However, this review did not solely look at RCTs and interventions meeting Seligman's criteria would not have been missed.

As mentioned before, current psychosocial care guidelines depend heavily on expert consensus and not on strong scientific evidence. They are rather evidence-informed than evidence-based. Although welcome as road maps, we must be aware of the "terra incognita" and continue our investment in learning from past experiences. Rigorous evaluation of effectiveness and its determinants is indispensable in order to enhance the map and thus the quality of post-disaster psychosocial care. For instance, the relevance of risk- and crisis communication after a CBRN disaster is not disputed; at the same time, not one risk- or crisis communication strategy in case of CBRN events has been tested on (cost-)effectiveness. Potentially, this knowledge would not only be valuable to help people overcome their problems, it will also protect them from ineffective interventions. Given the number of potential precipitants involved and the considerable revenues and recourses psychosocial interventions this will demand, it is important for society to gain knowledge on the cost-effectiveness of interventions.

\section{CONCLUSION}

Regarding the psychosocial consequences of CBRN events, Wessely (2005) concludes, "The acute effects will be less than we fear and the long-term effects more insidious and difficult to manage than we imagine". We are convinced that evidence-informed knowledge on interventions after CBRN events will help authorities and professionals to manage these effects. This study focused primarily on psychosocial care and not on the nature or prevalence of mental, behavioural or social problems that can arise after a CBRN disaster or event. Other studies, including many of the ones cited, have done this thoroughly. Our aim was to bring together the international body of knowledge on psychosocial interventions after a CBRN event, to identify gaps in the research and to identify recommendations for optimal psychosocial care. We found 39 publications containing suggestions and recommendations for different actors at different positions in the multi-layered postdisaster psychosocial care delivery system. When it comes to sketching an image of 
Gouweloos, J., Dückers, M., Brake, H. te, Kleber, R., Dorgendijk, A. Psychosocial care to affected citizens and communities in case of CBRN incidents: a systematic review.

Environmental International: 2014, 72, 46-65

the probable tasks and challenges, we could gratefully build upon the work of the various authors. However, when it comes to the evidence on effectiveness we cannot do anything else than be modest when recommending what to do and how to do it.

\section{REFERENCES}

Alexander, 2002

D. Alexander

Principles of emergency planning and management, Oxford University Press, New York (2002)

Alexander and Klein, 2003

D.A. Alexander, S. Klein

Biochemical terrorism: too awful to contemplate, too serious to ignore: subjective literature review

Br J Psychiatry, 183 (2003), pp. 491-497

American Psychiatric Association, 2013

American Psychiatric Association

Diagnostic and statistical manual of mental disorders (5th ed.), American Psychiatric

Publishing, Arlington (2013)

Auvinen et al., 2001

A. Auvinen, M. Vahteristo, H. Arvela, M. Suomela, R. Rahola, M. Hakama, et al.

Chernobyl fallout and outcome of pregnancy in Finland

Environ Health Perspect, 109 (2001), pp. 179-185

Becker, 2005

S.M. Becker

Addressing the psychosocial and communication challenges posed by radiological/nuclear terrorism: key developments since NCRP report no. 138

Health Phys, 89 (2005), pp. 521-530

Benedek et al., 2002

D.M. Benedek, H.C. Holloway, S.M. Becker

Emergency mental health management in bioterrorism events

Emerg Med Clin North Am, 20 (2002), pp. 393-407

Bertollini et al., 1990

R. Bertollini, D. DiLallo, P. Mastroiacovo, C. Perucci

Reduction of births in Italy after the Chernobyl accident

Scand J Work Environ Health, 16 (1990), pp. 96-101

Bisson et al., 2010

J.I. Bisson, B. Tavakoly, A.B.. Witteveen, D. Adjdukovic, L. Jehel, V.J. Johansen, et al.

TENTS guidelines: development of post-disaster psychosocial care guidelines through a

Delphi process

Br J Psychiatry, 196 (2010), pp. 69-74

Blanchard et al., 2005

J.C. Blanchard, Y. Haywood, B.D. Stein, T.L. Tanielian, M. Stoto, N. Lurie

In their own words: lessons learned from those exposed to anthrax

Am J Public Health, 95 (2005), pp. 489-495

Bonanno et al., 2010

G.A. Bonanno, C.R. Brewin, K. Kaniasty, A.M. La Greca

Weighing the costs of disaster: consequences, risks, and resilience in individuals, families, and communities

Psychol Sci Public Interest, 11 (2010), pp. 1-49

Bromet, 2012

E.J. Bromet

Mental health consequences of the Chernobyl disaster

J Radiol Prot, 32 (2012), pp. N71-N75

Bromet and Havenaar, 2009

E.J. Bromet, J.M. Havenaar

The long-term mental health impact of the Chernobyl accident 
Gouweloos, J., Dückers, M., Brake, H. te, Kleber, R., Dorgendijk, A. Psychosocial care to affected citizens and communities in case of CBRN incidents: a systematic review.

Environmental International: 2014, 72, 46-65

Y. Neria, S. Galea, F.H. Norris (Eds.), Mental health and disasters, Cambridge University

Press, Cambridge (2009), pp. 441-453

Considine and Mitchell, 2009

C. Considine, B. Mitchell

Chemical, biological and radiological incidents: preparedness and perceptions of emergency nurses

Disasters, 33 (2009), pp. 482-497

Cowan et al., 2005

A.E. Cowan, P.L. Ching, S.J. Clark, A.R. Kemper

Willingness of private physicians to be involved in smallpox preparedness and response activities

Biosecur Bioterror, 3 (2005), pp. 16-22

Cwikel et al., 2002

J.G. Cwikel, J.M. Havenaar, E.J. Bromet

Understanding the psychological and societal response of individuals, groups, authorities, and media to toxic hazards

J.M. Havenaar, J.G. Cwikel, E.J. Bromet (Eds.), Toxic turmoil: psychological and societal consequences of ecological disasters, Kluwer Academic/Plenum Publishers, New York (2002), pp. 39-65

DiGiovanni, 2003

C. DiGiovanni Jr.

The spectrum of human reactions to terrorist attacks with weapons of mass destruction:

early management considerations

Prehosp Disaster Med, 18 (2003), pp. 253-257

Dodgen et al., 2011

D. Dodgen, A.E. Norwood, S.M. Becker, J.T. Perez, C.K. Hansen

Social, psychological, and behavioral responses to a nuclear detonation in a US city:

implications for health care planning and delivery

Disaster Med Public Health Prep, 5 (Suppl. 64) (2011)

Dückers, 2013

M.L.A. Dückers

Five essential principles of post-disaster psychosocial care: looking back and forward with Stevan Hobfoll

Eur J Psychotraumatol, 4 (2013), p. 21914

Durodie, 2004

B. Durodie

Facing the possibility of bioterrorism

Curr Opin Biotechnol, 15 (2004), pp. 264-268

Eccles et al., 2003

M. Eccles, J. Grimshaw, M. Campbell, C. Ramsay

Research designs for studies evaluating the effectiveness of change and improvement strategies

Qual Saf Health Care, 12 (2003), pp. 47-52

Engel et al., 2004

C.C. Engel, A. Jaffer, J. Adkins, J.R. Riddle, R. Gibson

Can we prevent a second 'Gulf War syndrome'? Population-based healthcare for chronic idiopathic pain and fatigue after war

Adv Psychosom Med, 25 (2004), pp. 102-122

Engel et al., 2006

C.C. Engel, K.C. Hyams, K. Scott

Managing future Gulf War syndromes: international lessons and new models of care

Philos Trans R Soc Lond B Biol Sci, 361 (2006), pp. 707-720

Engel et al., 2007

C.C. Engel, S. Locke, D.B. Reissman, R. DeMartino, I. Kutz, M. McDonald, et al.

Terrorism, trauma, and mass casualty triage: how might we solve the latest mind-body problem?

Biosecur Bioterror, 5 (2007), pp. 155-163

Fullerton et al., 2004 
Gouweloos, J., Dückers, M., Brake, H. te, Kleber, R., Dorgendijk, A. Psychosocial care to affected citizens and communities in case of CBRN incidents: a systematic review.

Environmental International: 2014, 72, 46-65

C.S. Fullerton, R.J. Ursano, A.E. Norwood

Planning for the psychological effects of bioterrorism

R.J. Ursano, A.E. Norwood, C.S. Fullerton (Eds.), Bioterrorism: psychological and public health interventions, Cambridge University Press, New York (2004), pp. 2-14

Grievink et al., 2007

L. Grievink, P.G. Van der Velden, R.K. Stellato, A. Dusseldorp, B.P.R. Gersons, R.J. Kleber, et al.

A longitudinal comparative study of the physical and mental health problems of affected residents of the firework disaster Enschede, the Netherlands

Public Health, 121 (2007), pp. 367-374

Hall et al., 2002

M.J. Hall, A.E. Norwood, C.S. Fullerton, R.J. Ursano

Preparing for bioterrorism at the state level: report of an informal survey

Am J Orthopsychiatry, 72 (2002), pp. 486-491

Hall et al., 2004

M.J. Hall, A.E. Norwood, C.S. Fullerton, R. Gifford, R.J. Ursano

The psychological burden of bioterrorism

J Aggress Maltreat Trauma, 9 (2004), pp. 293-304

Havenaar and Van den Brink, 1997

J.M. Havenaar, W. Van den Brink

Psychological factors affecting health after toxicological disasters

Clin Psychol Rev, 17 (1997), pp. 359-374

Havenaar et al., 1996

J.M. Havenaar, W. Van Den Brink, J. Van Den Bout, A.P. Kasyanenko, N.W. Poelijoe, T.

Wohlfarth, et al.

Mental health problems in the Gomel region (Belarus): an analysis of risk factors in an area affected by the Chernobyl disaster

Psychol Med, 26 (1996), pp. 845-855

Hick et al., 2011

J.L. Hick, D.M. Weinstock, C.N. Coleman, D. Hanfling, S. Cantrill, I. Redlener, et al.

Health care system planning for and response to a nuclear detonation

Disaster Med Public Health Prep, 5 (Suppl. 88) (2011)

Hobfoll et al., 2007

S.E. Hobfoll, P. Watson, C.C. Bell, R.A. Bryant, M.J. Brymer, M.J. Friedman, et al.

Five essential elements of immediate and mid-term mass trauma intervention: empirical evidence

Psychiatry, 70 (2007), pp. 283-315

Holloway et al., 2002

H.C. Holloway, A.E. Norwood, C.S. Fullerton, C.C. Engel, R.J. Ursano

The threat of biological weapons: prophylaxis and mitigation of psychological and social consequences

J Am Med Assoc, 278 (2002), pp. 425-427

Hyams et al., 2002

K.C. Hyams, F.M. Murphy, S. Wessely

Responding to chemical, biological, or nuclear terrorism: the indirect and long-term health effects may present the greatest challenge

J Health Polit Policy Law, 27 (2002), pp. 273-291

Impact, 2007

Impact

Multidisciplinaire richtlijn vroegtijdige psychosociale interventies na rampen, terrorisme en andere schokkende gebeurtenissen, Trimbos Institute, Utrecht (2007)

International Federation of the Red Cross and Red Crescent Societies, 2005

International Federation of the Red Cross and Red Crescent Societies

World disaster report

Focus on information in disasters, IFRC, Geneva (2005)

Johnson et al., 2006

A. Johnson, J.L. Howe, M.R. McBride, B.R. Palmisano, E.A. Perweiler, R.E. Roush, et al. 
Gouweloos, J., Dückers, M., Brake, H. te, Kleber, R., Dorgendijk, A. Psychosocial care to affected citizens and communities in case of CBRN incidents: a systematic review.

Environmental International: 2014, 72, 46-65

Bioterrorism and Emergency Preparedness in Aging (BTEPA): HRSA-funded GEC collaboration for curricula and training

Gerontol Geriatr Educ, 26 (2006), pp. 63-86

Kikuchi and Kikuchi, 2012

S. Kikuchi, T. Kikuchi

The medical association activity and pediatric care after the earthquake disaster in

Fukushima

Keio J Med, 61 (2012), pp. 23-27

Knudsen, 1991

L. Knudsen

Legally-induced abortions in Denmark after Chernobyl

Biomed Pharmacother, 45 (1991), pp. 229-232

Knudson, 2001

G.B. Knudson

Nuclear, biological, and chemical training in the U.S. army reserves: mitigating psychological consequences of weapons of mass destruction

Mil Med, 166 (Suppl. 5) (2001)

Lemyre et al., 2005

L. Lemyre, M. Clement, W. Corneil, L. Craig, P. Boutette, M. Tyshenko, et al.

A psychosocial risk assessment and management framework to enhance response to CBRN terrorism threats and attacks

Biosecur Bioterror, 3 (2005), pp. 316-330

Lemyre et al., 2010a

L. Lemyre, W. Corneil, C. Johnson, P. Boutette

Psychosocial considerations about children and radiological events

Radiat Prot Dosimetry, 142 (2010), pp. 70-76

Lemyre et al., 2010b

L. Lemyre, C. Johnson, W. Corneil

Psychosocial considerations for mass decontamination

Radiat Prot Dosimetry, 142 (2010), pp. 17-23

Markel et al., 2008

G. Markel, A. Krivoy, E. Rotman, O. Schein, S. Shrot, T. Brosh-Nissimov, et al.

Medical management of toxicological mass casualty events

Isr Med Assoc J, 10 (2008), pp. 761-766

Neria et al., 2008

Y. Neria, A. Nandi, S. Galea

Post-traumatic stress disorder following disasters: a systematic review

Psychol Med, 38 (2008), pp. 467-480

Neria et al., 2009

Y. Neria, S. Galea, F.H. Norris

Mental health and disasters, Cambridge University Press, Cambridge (2009)

Norris et al., 2002a

F.H. Norris, M.J. Friedman, P.J. Watson

60,000 disaster victims speak: part II. Summary and implications of the disaster mental

health research

Psychiatry, 65 (2002), pp. 240-260

Norris et al., 2002b

F.H. Norris, M.J. Friedman, P.J. Watson, C.M. Byrne, E. Diaz, K. Kaniasty

60,000 disaster victims speak: part I. An empirical review of the empirical literature, 19812001

Psychiatry, 65 (2002), pp. 207-239

Noy, 2004

S. Noy

Minimizing casualties in biological and chemical threats (war and terrorism): the importance of information to the public in a prevention program

Prehosp Disaster Med, 19 (2004), pp. 29-36

NSW Institute of Psychiatry and Centre for Mental Health, 2000

NSW Institute of Psychiatry and Centre for Mental Health 
Gouweloos, J., Dückers, M., Brake, H. te, Kleber, R., Dorgendijk, A. Psychosocial care to affected citizens and communities in case of CBRN incidents: a systematic review.

Environmental International: 2014, 72, 46-65

Disaster Mental Health Response Handbook, New South Wales Health, North Sydney (2000)

O'Boyle et al., 2006

C. O'Boyle, C. Robertson, M. Secor-Turner

Public health emergencies: nurses' recommendations for effective actions

AAOHN J, 54 (2006), pp. 347-353

Ohbu et al., 1997

S. Ohbu, A. Yamashina, N. Takasu, T. Yamaguchi, T. Murai, K. Nakano, et al.

Sarin poisoning on Tokyo subway

South Med J, 90 (1997), pp. 587-593

Oordt, 2006

M.S. Oordt

The psychological effects of weapons of mass destruction

C.H. Kennedy, E.A. Zillmer (Eds.), Military psychology: clinical and operational applications,

Guilford Press, New York (2006), pp. 295-309

Pastel and Ritchie, 2006

R.H. Pastel, E.C. Ritchie

Mitigation of psychological effects of weapons of mass destruction

E.C. Ritchie, P.J. Watson, M.J. Friedman (Eds.), Interventions following mass violence and disasters: strategies for mental health practice, Guilford Press, New York (2006), pp. 300318

Petterson, 1988

J.S. Petterson

Perception vs. reality of radiological impact: the Goiania model

Nucl News, 31 (1988), pp. 84-90

Plum and Veenema, 2003

K.C. Plum, T.G. Veenema

Management of psychological effects

T.G. Veenema (Ed.), Disaster nursing and emergency preparedness for chemical, biological and radiological terrorism and other hazards, Springer, New York (2003)

Reid et al., 2005

W.M. Reid, S. Ruzycki, M.L. Haney, L.M. Brown, J. Baggerly, N. Mescia, et al.

Disaster mental health training in Florida and the response to the 2004 hurricanes

J Public Health Manag Pract (2005), pp. S57-S62 [Suppl.]

Ritchie et al., 2004

E.C. Ritchie, M. Friedman, P. Watson, R. Ursano, S. Wessely, B. Flynn

Mass violence and early mental health intervention: a proposed application of best practice guidelines to chemical, biological, and radiological attacks

Mil Med, 169 (2004), pp. 575-579

Rokach et al., 2010

A. Rokach, R. Cohen, N. Shapira, S. Einav, A. Mandibura, Y. Bar-Dayan

Preparedness for anthrax attack: the effect of knowledge on the willingness to treat patients Disasters, 34 (2010), pp. 637-643

Rubin et al., 2012

G.J. Rubin, A.K. Chowdhury, R. Amlôt

How to communicate with the public about chemical, biological, radiological, or nuclear

terrorism: a systematic review of the literature

Biosecur Bioterror, 10 (2012), pp. 383-395

Scharoun and Dziegielewski, 2010

K. Scharoun, S.F. Dziegielewski

Bioterrorism and the emergency room: planning for the unexpected

Stress Trauma Crisis Int J, 7 (2010), pp. 135-150

Seligman, 1995

M.E.P. Seligman

The effectiveness of psychotherapy. The consumer reports study

Am Psychol, 50 (1995), pp. 965-974

Sheppard et al., 2006

B. Sheppard, G.J. Rubin, J.K. Wardman, S. Wessely 
Gouweloos, J., Dückers, M., Brake, H. te, Kleber, R., Dorgendijk, A. Psychosocial care to affected citizens and communities in case of CBRN incidents: a systematic review.

Environmental International: 2014, 72, 46-65

Terrorism and dispelling the myth of a panic prone public

J Public Health Policy, 27 (2006), pp. 219-245

Smith et al., 2011

E.C. Smith, F.M. Burkle Jr., F. Archer

Fear, familiarity, and the perception of risk: a quantitative analysis of disaster-specific concerns of paramedics

Disaster Med Public Health Prep, 5 (2011), pp. 46-53

Smithson and Levy, 1999

A. Smithson, L.-A. Levy

Rethinking the lessons of Tokyo

A. Smithson, L.-A. Levy (Eds.), Ataxia, the chemical and biological terrorism threat and the

U.S. response, report no. 35, Henry L. Stimson Center, Washington DC (1999), pp. 71-111

Sohier and Hardeman, 2006

A. Sohier, F. Hardeman

Radiological dispersion devices: are we prepared?

J Environ Radioact, 85 (2006), pp. 171-181

Te Brake and Dückers, 2013

H. Te Brake, M. Dückers

Early psychosocial interventions after disasters, terrorism and other shocking events: is there a gap between norms and practice in Europe?

Eur J Psychotraumatol, 4 (2013)

http://dx.doi.org.ezproxy.library.wur.nl/10.3402/ejpt.v4i0.19093

Te Brake et al., 2009

H. Te Brake, M. Dückers, M. De Vries, D. Van Duin, M. Rooze, C. Spreeuwenberg

Early psychosocial interventions after disasters, terrorism, and other shocking events:

guideline development

Nurs Health Sci, 11 (2009), pp. 336-343

Tinker and Vaughan, 2004

T.L. Tinker, E. Vaughan

Communicating the risks of bioterrorism

R.J. Ursano, A.E. Norwood, C.S. Fullerton (Eds.), Bioterrorism: psychological and public health interventions, Cambridge University Press, New York (2004), pp. 308-329

Ursano et al., 2002

R.J. Ursano, C.S. Fullerton, A.E. Norwood

Responding to bioterrorism: individual and community needs, Uniformed Services University of the Health Sciences, Bethesday MD (2002)

Vazquez et al., 2010

M. Vazquez, O. Jordan, E. Kuper, D. Hernandez, M. Galmarini, A. Ferraro

Management of acute traumatic stress in nuclear and radiological emergencies

Health Phys, 98 (2010), pp. 795-798

Weisaeth and Tonnessen, 2003

L. Weisaeth, A. Tonnessen

Responses of individuals and groups to consequences of technological disasters and radiation exposure

A.E. Norwood (Ed.), Terrorism and disaster: individual and community mental health interventions, Cambridge University Press, New York (2003), pp. 209-235

Wessely, 2005

S. Wessely

Don't panic! Short and long term psychological reactions to the new terrorism: the role of information and the authorities

J Ment Health, 14 (2005), pp. 1-6

Williams and Williams, 2010

G. Williams, E. Williams

A nursing guide to surviving a radiological dispersal device

Br J Nurs, 19 (2010), pp. 24-27

Witteveen et al., 2012

A.B.. Witteveen, J.I. Bisson, D. Ajdukovic, F.K. Arnberg, K. Bergh Johannesson, H.B.

Bolding, et al. 
Gouweloos, J., Dückers, M., Brake, H. te, Kleber, R., Dorgendijk, A. Psychosocial care to affected citizens and communities in case of CBRN incidents: a systematic review.

Environmental International: 2014, 72, 46-65

Post-disaster psychosocial services across Europe: the TENTS project

Soc Sci Med, 75 (2012), pp. 1708-1714

Wodarski, 2004

J.S. Wodarski

Preparing social services and public services professionals for meaningful roles in disaster services

Stress Trauma Crisis Int J, 7 (2004), pp. 209-222

World Health Organization (WHO), 2013

World Health Organization (WHO)

Guidelines of the management of conditions specifically related to stress, WHO, Geneva (2013)

World Trade Organization (WTO), 2012

World Trade Organization (WTO)

World trade report 2012. Trade and public policies. A closer look at non-tariff measures in

the 21st century, WTO, Geneva (2012)

Wynia and Gostin, 2004

M.K. Wynia, L.O. Gostin

Ethical challenges in preparing for bioterrorism: barriers within the health care system

Am J Public Health, 94 (2004), pp. 1096-1102

\section{TABLES}

Table 1

Principal recommendations of the TENTS guidelines.

Multi-agency planning group: every area should have a multi-agency psychosocial care planning group that includes mental health professionals with expertise in traumatic stress who have a designated responsibility for psychosocial care following disasters and major incidents. Individuals affected by disasters or major incidents should also be represented. Psychosocial care plan: every area should have guidelines on the provision of psychosocial care in emergencies (a psychosocial care plan) that are incorporated into the overall disaster/major incident plan and regularly updated.

Training and supervision: all care providers should have undergone formal training and receive on-going training, support and supervision.

Response: the response should promote a sense of safety, self and community efficacy/empowerment, connectedness, calm and hope. Responses should provide general support, access to social support, physical support and psychological support

Formal early interventions for all: provision of specific formal interventions such as single session individual psychological debriefing for everyone affected should not occur. Social support: efforts should be made to identify the correct supportive resources (e.g. family, community, school, and friends).

One-stop shop: a humanitarian assistance centre/one-stop shop should be established where a range of services potentially required can be based.

Symptomatic individuals: ind ividuals with psychosocial difficulties should be formally assessed by a trained professional with consideration for their physical, psychological and social needs before receiving any specific intervention.

Trauma-focused cognitive-behavioural therapy (CBT): treatment with trauma-focused CBT should be available for individuals with acute stress disorder or acute post-traumatic stress disorder (PTSD).

Other evidence-based treatments: other treatments with an evidence base for chronic PTSD should be available for individuals with acute PTSD when trauma-focused CBT is not available or is not tolerated.

Evidence-based interventions for individuals with other mental health difficulties should be available.

Long-term coordinated planning and cooperation: detailed planning should occur with local authorities/governments and existing services to fund and provide appropriate extra provisions to support local services for several years following the disaster.

Table 2
Search strategy used to identify studies for inclusion.

$1 \quad$ Key words related to CBRN events

CBRN OR CBRNe OR NBC OR WMD OR chemic" OR biologic" OR radiologic" OR radioactive OR nuclear OR "weapons of mass destruction" OR "explosive agents"

OR bombs OR "nuclear weapons" OR "biological warfare" AND emergencies OR terrorism OR terror OR attack OR accident OR disaster OR calamity OR emergency OR critical care OR crisis OR war OR battle OR combat OR confrontation OR confronted OR exposure

2

Key words related to psychosocial interventions

"Psycho social" OR psychosocial OR psychological OR social OR emotional OR "psychosocial deprivation" AND prevent" OR "prevention and control" OR protect"

OR detect OR identify" OR screen ${ }^{*}$ OR reduce ${ }^{*}$ OR mitigate OR ameliorate* OR monitor OR track OR training OR trained

1 AND 2

Limits Date of publication: 2000-2013, abstract available, English language, human

" : zero or more characters can be added in the search. For instance: there will also be searched for "chemical". 
Gouweloos, J., Dückers, M., Brake, H. te, Kleber, R., Dorgendijk, A. Psychosocial care to affected citizens and communities in case of CBRN incidents: a systematic review. Environmental International: 2014, 72, 46-65

Appendix A. EPOC criteria for reviews, RCTs, CBAs and ITSs

\begin{tabular}{|c|c|}
\hline Study design & Criteria \\
\hline Review & $\begin{array}{l}\text { a. Eligibility was scored by at least two authors; } \\
\text { b. Authors used inclusion and exclusion criteria; } \\
\text { c. Designs were judged using predefined criteria (EPOC); } \\
\text { d. Findings were scored by at least two authors; } \\
\text { e. Authors used data extraction forms. }\end{array}$ \\
\hline Randomised controlled trial (RCT) & $\begin{array}{l}\text { a. Protection against selection bias; } \\
\text { b. Protection against contamination (e.g., randomising organisation/professionals rather|than individual patients); } \\
\text { c. Protection against exclusion bias; } \\
\text { d. Follow-up of patients or episodes of care; } \\
\text { e. Comparability of baseline measurements; } \\
\text { f. Protection against detection bias (blinded assessment of primary outcomes; } \\
\text { g. Reliability of primary outcome measures. }\end{array}$ \\
\hline Controlled-before-and-after studies (CBA) & $\begin{array}{l}\text { a. Protection against contamination; } \\
\text { b. Protection against exclusion bias; } \\
\text { c. Follow-up of patients or episodes of care; } \\
\text { d. Comparability of baseline measurements; } \\
\text { e. Protection against detection bias; } \\
\text { f. Characteristics for studies using second site as control; } \\
\text { g. Reliability of primary outcome measures. }\end{array}$ \\
\hline Interrupted time series (ITS) & $\begin{array}{l}\text { a. Intervention is independent of other changes; } \\
\text { b. Data were analysed appropriately (ARIMA or time series regression); } \\
\text { c. Reason for the number of points preintervention and postintervention given; } \\
\text { d. Shape of the intervention effect was specified; } \\
\text { e. Intervention unlikely to affect data collection; } \\
\text { f. Protection against detection bias; } \\
\text { g. Completeness of data set; } \\
\text { h. Reliability of outcome measures. }\end{array}$ \\
\hline
\end{tabular}


Reference

(Intervention categorya; overall quality of design)

Alexander and Klein (2003)

$(1,2,3,4$; unsystematic literature review, weak)

Becker (2005)

(1, 2; expert opinion (meetings to develop the 'National Council on Radiation Protection and Measurements Report No. 138'), and description of interventions, weak)

\section{Benedek et al. (2002)}

$(1,2,3,4$; unsystematic literature review, weak)

Blanchard et al. (2005)

( 1 ; qualitative study using focus groups, weak)

Cwikel et al. (2002)

( 1 ; unsystematic literature review, weak)
Intervention

- Training and preparation for first responders should cover: information about reactions to stress, physical effects of toxic agents, decontamination procedures, psychological effects of barrier environments and practice with wearing protective equipment (as this can compromise physical function, communication with colleagues, and can cause overheating, hyperventilation and panic). - It is crucial to develop collaborative relationships with media to prevent distrust in authorities and uncertainty. The genera principles of crisis intervention and psychological first aid must be specified to bioterrorism.

pome of the most difficult aspects of consequence management may relate to the social and psychological after effects of an Sonic of the social

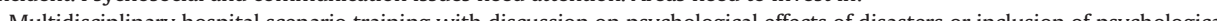

Multidisciplinary hospital scenario training with discussion of psychological effects of disasters or inclusion of psychological

- Policy and guidance development, including psychological and behavioural consequence management and managing stress in first responders (early interventions, risk communication);

Roundtables to identify hospital and clinician needs (internal and external communication, challenges faced, before, during an after an event) and development of a toolkit for hospitals and clinicians (communication, list of policy information officers and community resources; factsheets on radiation, contamination etc.);

- Surveys and focus groups among the public to understand their perceptions and concerns and improve risk communication - Integration of psychosocial and communication components into radiological terrorism preparedness and response plans.

- Unlike natural disasters, medical responders have a vital role in CBRN disaster and must be aware of this; they are the first to identify the consequences of the event and are challenged to address them.

- Although effective recognition, triage, and treatment are the most important aspects of emergency management, these efforts must be accompanied by measures aimed at mitigating rage, helplessness, and hopelessness associated with the experience of an attack or exposure.

- Many biological agents have been linked to psychopathologic problems and symptoms (anthrax, brucellosis, q-fever, botulinum toxic, viral encephalitis).

- Conservative use of prophylactic medication may reduce symptoms in exposed and uninfected individuals.

- There is no evidence that group debriefing techniques and critical incident debriefings reduce the development of psychiatric illness or prevent the development of PTSD. Nonetheless, evidence suggests that ongoing frank and open discussions among care providers and emergency responders (just as with other potential victims) foster cohesion and group understanding of the

providers and en
unfolding event.

Clear, consistent, accessible and reliable information from trusted sources will diminish public uncertainty.

- Train, prepare and organise care for medical responders. It is unrealistic to expect the medical staff to respond with empathy for their patients if their own emotional needs are ignored.

- Social, psychotherapeutic and psychopharmacological treatments are necessary for some patients. Preventive strategies must take into account that specific groups are at high risk for psychiatric morbidity, such as first responders and healthcare providers. These and other specific risk groups will benefit from the same interventions developed for the community as a whole.

- Consistency of messages across all groups affected is paramount to encouraging trust. In the event of uncertainty, it is importan to be honest and provide reliable updates.

- Communication efforts should closely involve people within the community (also the workspace) of exposed individuals.

- The community should be involved in helping to devise plans for intervention, treatment and communication.

- Future communication efforts must also consider the diversity of individuals who might be affected.

- Since typically some health services are already functioning, the first step after a disaster is to designate one central information centre and additional centres, clinics, or telephone lines available for those needing help to cope with the disaster.

- Authorities and media require a thorough understanding of scientific issues, and need to be able to communicate quickly with reliable and specific information to the lay public. They must maintain their trustworthiness and adequately influence the assumption of risk or lack of risk in the population and high risk groups.

Involve community members in the design, implementation and analysis of risk communication

- There should be a clear public body from the government responsible for communication with the affected public

- When many sectors are involved, it is critical to coordinate the media contact and information release.

- The media can play a pivotal role in either providing responsible information on the situation or inflating rumours that increase anxiety.

- Advocacy groups are very effective in making sure that problems affecting the exposed population are not forgotten and taken off the public agenda.
Type of event focused on

Type of event focused on
Event knowledge originated from

Recommendations directed at

Biological or chemical terrorism

Combination: CBRN events and general disasters/

terrorism, such as 9/11, Tokyo Sarin attacks, Cherno-

byl disaster

Authorities and mental health agencies

Radiological or nuclear terrorism

$\mathrm{n} / \mathrm{a}$

ities (federal, local and state agencies) hospitals

\section{Bioterrorism}

Combination: CBRN events and general disasters/

terrorism

Medical emergency responders

Public health emergencies

U.S. Anthrax Attacks

Communicators (all those involved in

communication about the event)

Ecological disasters

Combination: CBRN events such as Chernobyl disas-

ter (main source), Hiroshima and Nagasaki bomb-

ings, Gulf War and Three Mile Island

Authorities, media and advocacy groups 
DiGiovanni (2003)

$(1,2,3,4$; unsystematic literature review and expert opinion (workshop of the U.S. government and Red Cross to find consensus on early interventions after traumatic events), weak)

Dodgen et al. (2011)

$1,2,3,4$; unsystematic literature review and expert opinion (e.g. personal communication, reports of expert meetings), weak

Durodie (2004)

(1; unsystematic literature review, weak)

Engel et al. $(2004,2006)$

(4; unsystematic literature review, weak)

Engel et al. (2007)

4; unsystematic literature review and expert opinion (meetings of the "Working Croup on Psychiatric Screening and Triag during Ter Attacks'), weak)

\section{Fullerton et al. (2004)}

$(1,2,4$; unsystematic literature review, weak
- To manage patients, accurate triage is important: distinguish those with psychiatric symptoms because of anxiety/fear from those who show psychiatric symptoms due to exposure to an agent. Some agents also cause psychological effects.

- Mental health resources must be allocated and utilised.

- When offering early psychological interventions: 1 . professionals should be aware that most distressed victims do not develop mental disorders, 2 interventions should be voluntary, 3 early brief and focused psychotherapy can reduce distress in victim ho suffered losses, 4 , single one-to-one recital of tram problems, and 5. not all publicised early interventions are proven to be effective.

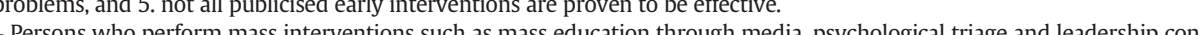
tation should have the knowledge and accountability to do so, for they may cause harm

tation should have the knowledge and accountability to do so, for they may cause harm. For acute response

- Address psychological barriers to protective behaviour (e g. adhering guidance to shelter, wearing protection);

- Address psychological barriers to protective behaviour (e.g. adhering guidance to shelte,
- Discourage dangerous behaviour (e.g. searching for loved ones in high radiation areas);

- Discourage dangerous behaviour (e.g. searching for loved ones
- Manage patient/survivor flows to diminish surge on hospitals:

- Support first responders with training (also because it reduces uncertainty and stress);

- Facilitate medical and psychological triage;

- Strengthen resilience by promoting the five "essential principles" (a sense of safety, calm, self- and group-efficacy, connectedness with others and hope):

- Target psychiatric disorders (including medically unexplained physical symptoms);

- Provide evidence-based early psychological treatment.

- Increase resilience and confidence across society by restoring a sense of common purpose and active political engagement.

- Political leadership cannot be short-circuited by technical means of information campaigns.

A multi-layered population based healthcare model is developed to prevent and mitigate idiopathic symptoms after war (not specifically (BRN). The model consists of 4 steps:

1. Start with post-war preclinical prevention to reduce incidence and prevalence of idiopathic symptoms. Approach: general prevention efforts on exposures and proximity of exposure to traumatic events or hazardous exposures (e.g. screening and education at the workplace, informal 'lay' debriefings, family education and support networks).

. Provide routine primary care symptom mitigation to identify and reduce the prevalence of idiopathic symptoms. Approach: primary care provider delivers diagnostic services, low intensity treatments and psychosocial support.

3. Provide collaborative primary care to reduce the prevalence of idiopathic symptoms and prevent disability. Approach: interdisciplinary practice teams intensify care in coordination with primary care provider (e.g. patient education regarding symptom and disability, physical and psychosocial reactivation efforts, negotiated goal setting, collaborative problem-solving).

4. Provide intensive rehabilitation to reduce morbidity. Approach: specialised multidisciplinary and multifaceted rehabilitative programmes (e.g. 3-4 week inpatient or 10-15 weeks weekly ambulatory care, structured and behavioural intensive rehabilitation efforts, graduated return to work, planned practice team follow-up).

A healthcare system response model with four levels is proposed that addresses the identification and treatment of mass idiopathic illness.

- Level 1: distance assessment with an initial remote contact (e o telephone or internet). Identify those who need immediate Leve 1 . distance assessment with a

in the cling looks for acute unstable medical or surgical disease and hose who need Level 2. brief medical asses

medical attention.

Level 3: clinician obtains a review of systems (symptom count) and assesses health anxiety based on standardised

measurement tools (screening) and a more detailed physical examination. Identify idiopathic symptoms.

- Level 4: Primary care for people with idiopathic symptoms. This will consist of watchful waiting including scheduled visits, selfcare instruction and the provision of health information. Early voluntary psychiatric consultation could reduce symptoms.

Several assessment tools are proposed for idiopathic physical symptoms, psychiatric distress, psychiatric disorders, and worry about illness and conviction.

- Traditional natural disaster models of health care have limited applicability in bioterrorism.

- The mental health care system must join with the public health and emergency response system to address the need for triage, surge capacity and health surveillance.

- Mental health intervention must target the community and vulnerable groups of directly exposed, those with pre-existing mental health problems and those with limited support systems and recourses.

- Mental health intervention includes prompt medical response to a bioterrorist attack. This will increase the public sense of safety and confidence in institutions.

- Institutions must be trained and prepared to be able to respond to the sudden surge need of victims to prevent organisation panic.
Attacks with weapons of mass destruction using chemical, biological and radiological agents Combination: CBRN events and general disasters/

Mental health professionals, people responsible for the early management of a disaster

\section{Nuclear detonation}

Combination: CBRN events and general disasters/ terrorism, such as bombings on Nagasaki and Hiroshima and 9/11

Behavioural health care providers

\section{Bioterrorism}

Combination: CBRN events and general disasters/

terrorism such as 9/11, US. Anthrax attacks, Gulf wa

Politicians

War

Mental health professionals

Radiological, biological or chemical terrorist attacks Combination: CBRN events and general disasters/

Healthcare system

\section{Bioterrorism}

Combination: CBRN events and general disasters/ terrorism, war and outbreaks of diseases/pandemics Mental health professionals, public health professionals and emergency responders 
- Communication is a core principle of consequence risk management. The public will actively seek information on whether they are at risk and what they can do to protect themselves. Information about the source of exposure scope of the outbreak, numbe of people exposed, etc. is needed. Physicians play an important role in education about risk and prevention and can influence how people perceive risk and will behave.

Overall: educating the authorities and the public about bioterrorism takes out the mystery of microorganisms and prepares people to respond appropriately rather than irrationally.

Hall et al. (2002)

$(1,2$; qualitative study using an open ended questionnaire, weak)

Effective and accurate risk communication is a key early p

- Have an interagency emergency planning group;

- Develop plans and policies to address behavioural and mental health issues specific to bioterrorism; - Implement a risk communication programme;

- Implement communication plans to inform the public on psychological/behavioural issues;

- Make working agreements with the media that include mental health;

Be involved in bioterrorism training exercise (including risk communication and interaction with the media).

Mental health consultation to bioterrorism planning at all levels (federal, state and local) is crucial to mitigating psychosocia impact.

- Develop a risk communication plan and education to address issues like isolation, quarantine, administering vaccinations, and distributing medications.

- Early mental health interventions should identify symptoms and behaviours linked to psychological distress and suggest strategies to restore well-being.

Hick et al. (2011)

$(1,2,3$; unsystematic literature review, weak $)$
Hyams et al. (2002)

(1,2; unsystematic literature review, weak)
Public communication, both basic information and risk communication, should be used to reduce unnecessary demands on the medical system. This should be coordinated with governmental messaging.

Key principles during the recovery phase:

- Medical monitoring and care will be ongoing and, in some cases, complex

Social and behavioural health issues will become dominant after the initial acute medical care period and will require multidisciplinary approaches;

- Family reunification system will need to be activated and aggressively implemented

- Continuity of access to health care and essential social systems will be essential to meet victim needs;

- A rapid return to a state of normalcy with respect to appropriate permanent housing, schooling, community services, and othe essential systems will be essential to reduce the long-term psychological impact on children and families;

- A significant portion of the evacuees will be permanently displaced, posing significant problems with the continuity of their complex medical and social care;

- Long-term monitoring should be done for those deemed to be at risk for late radiation-induced damage or cancer. Those who require monitoring will require expert input from epidemiologists;

- long-term follow-up and registries will be needed for other physical injuries and psychiatric support.

A community confronted with a CBRN threat needs both emergency intervention and long-term healthcare, extensive medica and risk assessment information, and economic support. Multiple challenges to the credibility of governmental and scientific cation and management and 3) surveillance and research.

Health care

Clinical care and specially trained providers must be readily available to meet the community's health care needs and restore confidence in public institutions.

- Health care has to be furnished by private physicians, health maintenance organisations or federal health care systems.

- To ensure access to health care, well-trained personnel and early identification of worsening health problems, health care hould be centralised in local medical facilities.

Offering mental health care shortly after mass terror is important; however immediate grief counselling or psychological debriefing may not be effective.

Risk communication and Management

- Primary method for rapidly disseminating information is through the popular news media

- Public officials and scientific experts have to be as open, clear and forthcoming as possible to the public and provide the press with the best available information: cooperate with the press, discourage false rumours but do not provide false reassurance.
Type of event focused on

Event knowledge originated from

\section{Bioterrorism}

State departments of mental health

\section{Bioterrorism}

Combination: CBRN events, pandemics and genera disasters/terrorism, such as U.S. Anthrax attacks, SARS pandemic, U.S. smallpox vaccination programme, Iraqi missile attacks on Israel, Tokyo Sarin attacks

People involved in planning for public's psychological and behavioural reactions

Nuclear detonation

Combination: CBRN events and general disasters/ terrorism, such as hurricane Katrina, terrorist attacks in Israel, 9/11, earthquakes, fires, Oklahoma City bombings

Emergency medical services

Chemical, Biological or Nuclear Terrorism Combination: CBRN events and general disasters/ terrorism, such as U.S. Anthrax Attacks, Gulf War, Tokyo Sarin Attacks, Chernobyl disaster, 9/11

Heath care system, government, authorities, experts, media 
Johnson et al. (2006)

(2; unsystematic literature review and expert

opinion (advice of U.S. Geriatric Education

(entres), weak)

Kikuchi and Kikuchi (2012)

$(3,4 ;$ no design described, description of an

intervention, weak)

Knudson (2001)

(2; unsystematic literature review, weak)

\section{Lemyre et al. (2005)}

$(1,2$; qualitative study (focus groups and public telephone survey), expert opinion (round table consultations) and unsystematic literature review, weak)

\section{Lemyre et al. (2010a)}

$(1,2,3,4$; unsystematic literature review, weak)
- The press has to educate itself about a new health threat in order to accurately report the news.

- Effective risk communication requires a two way exchange of information with the affected public: work closely with community leaders.

Government should take responsibility for its mistakes and clearly explain the reasons for critical decisions in order to maintain -

- For recovery of people's sense of control and resilience: risk management efforts have to prevent demoralisation and ensure that members of the affected population are characterised as survivors rather than victims.

- Rapid financial assistance and the rebuilding of the community's economy provide substantial health benefits.

Surveillance and research

- Identification of affected individuals should be based on the objective characteristics of the injury caused by the particular agen and should not rely on nonspecific symptoms that may be related to mass sociogenic illness: this will lead to misclassification and confusion among the public.

- Longitudinal surveillance studies should be initiated to generate evidence-based answers to questions about rates of exposure and diseases.

- Research should be initiated early and not in response to later media pressure. It is necessary not only to answer pressing health questions but as part of the risk-management process itself.

Elderly have complex physical social and psychological needs. Elders and persons with disabilities may need more preparation time, a variety of communication and warning modalities, availability of oxygen and respiratory equipment, training in alternative transfer techniques and exit routes, and assistance to maintain regularity in medication and treatment regimes.

- A trained workforce of interdisciplinary healthcare providers is essential to operationalise systems that are necessary to meet the needs of elders.

the needs of elders.

- Evidence-based guidelines are needed for emergency preparedness plans in various settings across the elder care continuun. - Medical and nonmedical professionals, policy-makers and researchers all have a role in meeting the needs of the elderly.

A programme was implemented to alleviate mental health problems in children by:

Distribution of leaflets on how to care for children with anxieties;

- Setting up children's play corners in evacuation shelters;

- Organising lectures by a children trauma specialist and a specialist in nuclear power accidents, non-fiction writer and facilitato of storybook reading;

- Organisation of two children's festivals to provide children with active indoor play and physical exercise.

Pregnant woman might suffer from anxiety concerning radiation exposure. Midwives can give advice to pregnant woman to relieve their worries.

U.S. army reserves play an important role in responding to an incident. They need training by engaging in realistic scenario exercises that puts theory into practice. This will help them gain proficiency in protective equipment and confidence in their medical support and will minimise psychological as well as physical casualties. A psychosocial risk assessment and management (P-RAM) framework is developed to help identify the full range of psychosocia aspects potentially associated with CBRN threats and attacks. Normal and abnormal psychosocial effects of a CBRN event (betime: pre-event (preparedness and planning, threat, warning), impact (impact) and post event (rescue, recovery, and recontime: pre-event (preparedness and planning, threat, warning), impact (impact) and post event (rescue, recovery, and recon-
struction)), population (community, individuals and vulnerable groups such as elderly, children and responders), and intervenstruction)), population (community, individuals and vulnerable groups such as elderly, children and responders), and interventions. Regarding the intervention, several relevant levels are distinguished within the framework: individual, community and
society. Psychosocial interventions can be aimed at these levels and at an organisational level. The interventions are subdivided society. Psychosocial inte
into four categories:

- Risk communication

- Education;

- Social support;

- Professional counselling.

Important, too, is that the framework recognises that the implementation of psychosocial or bioenvironmental interventions, may result in further psychosocial effects (for instance quarantine may result in social stigma: communication strategies that address stigma may be needed). A limitation is that the framework does not provide a detailed description of specific psychosocial interventions and the best way to apply them.

Psychosocial interventions for children

- General: Reunify children with their parents, preserve the family unit. Encourage expression through play and discussion with - General: Reunify children with their parents, preserve the family unit. Encourage expression through play and discussion with
parents and/or peers, give credible reassurance, clarify misconceptions, and encourage social activities.

- Fist responders. Be prepared for a lack of local paediatic specially resources and the fact that children require different intervention as they are affected differently. Drug treatments need to be modified because of children's decreased body mass, decontamination units need to be made fit to children (children are unable to self-decontaminate and children are at greater risk of hypothermia during decontamination), efforts must be made to keep families together, especially during decontamination an communication during evacuation procedures need to be prepared for fear of children to be disconnected with family
Biological terrorism

Combination: CBRN events and general disasters/ terrorism

Medical professionals

\section{Disasters and crisi}

Fukushima earthquake disaster that damaged

nuclear power plant

Physicians, psychologists, public health nurses,

childcare staff

Terrorist attacks with biological, toxic, chemical and nuclear weapons of mass destruction

Combination: war with and without use of CBRN

weapons

People responsible for the U.S. army reserves

CBRN threats and attacks

Combination: CBRN events and general disasters/

terrorism CBRN emergency responders, planners and decision-makers in different phases

\section{Radiological events}

Combination: CBRN events and general disasters/ terrorism, specifically Goiania Brazil, Oklahoma city bombings, Beslan, 9/11 and Chernobyl disaster First responders, (mental) health organisations, parents, media, schools 
Reference

(Intervention categorya; overall quality of design)

Intervention

Type of event focused on

Event knowledge originated from

Recommendations directed at

- Families: Workers are also parents and response plans must take into account the parental role of workers. Pregnant woman require special consideration because of the biological impact upon the unborn and because abortion rates may rise.

- Schools: Parents, teachers and counsellors should learn to differentiate stress reactions in children as they may differ from adults. They should know how to convey credible reassurance and foster a sense of safety while guiding children through aptection responses. Schools are ideal for exercises, education and drills and are vectors of preparedness for tadiological events.

- Media: Monitor news content and limit the amount of time children are exposed to traumatic imaginary on TV. Open discussion of news between parents and children is to be advocated. Media must monitor content shown and warn audiences to remove children. Media plays an important role in educating and preparing the public.

Lemyre et al. (2010b)

$(1,2,3,4$; unsystematic literature review, weak)

\section{Markel et al. (2008)}

(2; expert opinion (Armed Forces Radiobiolog

Research Institute conference in 2000), weak)

Noy (2004)

$(1,2$; unsystematic literature review, weak)

O'Boyle et al. (2006)

(2, 3; qualitative study using focus groups, weak)
- Perceptions matter: an effective risk communication strategy is needed because behaviour, worry and outrage are dependent - Perceptions matter: an effective risk communication strategy is needed because behaviour, worry and outrage are depen
on risk perceptions. Unclear information on contamination or decontamination can create distrust, uncertainty, and nonon risk perceptions. Unclear information on contamination or decontactic
adherence to advice (e.g. refusal to take prophylactic medication).

adherence to advice (e.g. refusal to take prophylactic medication).
- Screening people who are in fear of contamination but are not actually contaminated can reassure them and can increase trust - Screening people who are in fear of contamination but are not actually contaminated can reassure them and can increase trust
in public officials. Pre-screening using sensitive portal monitors may assist in separating those who fear contamination and those in public officials. Pre-sce
actually contaminated.

actually contaminated. - Provide good quality information to the medr
role of the media as protecting public good.

- Use social media to reach a larger public in a timely manner with preventive and mitigating recommendations.

- Given the impact of uncertainty upon risk perceptions, it is better to acknowledge what is not known as well as the steps that are being taken to handle a situation than to say nothing at all.

- Adapted behaviour from the public and compliance with authority guidelines for decontamination depends on public education and appropriate communication of risk pathways and protective measures.

- Enhancing a sense self-efficacy, agency, mastery through skill sets, shared expectations and preparedness training improves behavioural response.

- Pre-event reheala training improves performance, at a minimum, mental imagery, virtual drills, vicarious play in a secure environment will all help if actual enacting is not possible.

environ will do - People will do everything to get reunited with close ones. Keep families together during an extreme event, plan quarantine assistance to prevent the negative consequences of isolation does not overwhelm the emergency response system.

- It is inevitable to rely on community volunteers and this demands pre-planning, pre-training and education about emergency assistance and mass decontamination principles.

Citizens will rapidly overflow the hospitals with symptoms related to stress reaction (mainly acute stress reaction, anxiety with or without somatisation, and concerns for relatives).

- Concomitant to field rescue teams, mental health professionals should arrive at the hospitals,

- These teams should initiate treatment as soon as possible once the possibility of toxic exposure has been eliminated.

Implement a prevention programme, far in advance of a strike, relying on the premise that the public is rational and acts

adaptively and should take an active role in protecting itself and the community. The following ingredients are important:

- Early mobilisation of the medical system for prompt diagnoses and treatment;

- Early recruitment of detection service (police, emergency services, epidemiological centres, special laboratories);

- Early preparation of specific instructions to the population for the time of the strike:

- Slow dissemination of relevant information about the threat;

- Guidance using effective coping tools to the public (give information before critics discuss it,

- Do not withhold negative information);

- Informing the public correctly about the threat and the protective steps.

Preparation for emergencies should include assessment of nurses' or stakeholders' concerns. Specific measures can improve safety, reduce anxiety, increase trust in hospitals and provide physical and emotional support. Interventions that support nurses' ability to cope during bioterrorism are:

- Accessible and adequate protective equipment

Education and drills;

- Accessible information;

- Available content experts and available administrators;

- Increased security to protect nurses:

- Emotional and physical support;

- Communication with family;

- Commitment from institutions to care for ill or injured nurses. require mass decontamination
Radiological, biological or chemical events that

Combination: CBRN events and pandemics, such as Chernobyl disaster, Goiania, Brazil, Tokyo Sarin attacks, U.S. Anthrax attacks, Three Mile Island and the 2003 SARS pandemic

Responders, communicators, public officials, personnel of the healthcare and emergency infrastructure, public behaviou

Toxicological mass casualty events. $\mathrm{n} / \mathrm{a}$ Hospitals

Biological and chemical attacks

Combination: CBRN and general terrorism and war studies such as 9/11, Gulf War, U.S. Anthrax Attacks, Goiania Brazi

Leaders 
Reid et al. (2005)

(2; cross-sectional quantitative study, weak)

Ritchie et al. (2004)

$(1,3,4$; no design described, description of a scenario, weak)

Rubin et al. (2012)

(1; systematic review (studies included are qualitative studies, cross-sectional surveys or based on hypothetical scenarios), weak)
Many of the psychological effects of weapons of mass destruction in the military population are the result of wearing or using protective equipment. Effective functioning compromised people wearing protective clothing and a gas mask. To decrease anxiety of wearing gas mask it is advised to provide:

- Stress inoculation training and frequent practice with gas masks;

- Psychological intervention involving relaxation techniques and systematic exposure in case of severe gas mask anxiety. Key preparation issues are to:

Prepare for effective communication with the public by community leaders who are able to maintain sources of emotional and practical support, and deal with fear and helplessness:

- Give psychologists a role in managing community reaction after CBRN attacks;

Create training scenarios that involve role players with emotional distress, psychiatric symptoms, and behavioural disturbances;

- Avoid use of quarantine, when possible, and instead use public education about exposure and request voluntary curtailment of travel;

- Ensure that all officials are aware of the basic principles of risk communication when working with the media, including the importance of expressing empathy to the public and providing accurate and honest information;

- develop a public education campaign on preparation for an event;

- educate and train first responders;

- establish a command and control centre to coordinate services and use of personnel;

- ensure the security of communication systems:

- plan for processing of the dead that is attentive to family wishes and customs.

Many psychological and medical effects can be prevented or mitigated by proper planning and practice prior to a CBRN event. Mental health care providers need to be integrated with disaster response plans and emergency rooms.

- Preparation: Planning should be done in many forms: education of the public, table-top exercises, disaster drills, practice performing tasks in protective equipment and mass casualty exercises. Consider the best way to inform the public about CBRN risks. Explore different types of scenarios, and the role different agencies will play as well as the obstacles (also jurisdictional). Emergency departments must be prepared for large amounts of people concerned about exposure. Medical and mental health care providers need to be trained (e.g. identification and differentiation of medical and psychological effects, attention to workers' concerns about exposure)

- Protection equipment issues: Organise routine, well-rehearsed training, replicating normal procedures to make staff members familiar with equipment.

-Risk perception and health risk communication: Daily or twice daily scheduled briefings with media and public is valuable (also if there is no information to share). The public should be provided with accurate information and workable solutions.

- Triage and issues of differential diagnoses: Identify and treat psychological symptoms at an early stage. Reassure that symptoms are normal after an abnormal event. Mental health care providers must be integrated in emergency rooms to remove psychological casualties from emergency rooms and take them to a less stressful environment.

A 5 day Bioterrorism Trauma Intervention Specialist Training is developed. It is not only useful for responding to bioterrorism but to all kinds of disasters. The training focuses on learning and practicing how to offer mental health interventions to victims. The training covers: assessment triage, early trauma intervention, debriefing Critical Incident Stress Management, compass.

fatigue, grief intervention, cultural competence and team development. It includes interactive methods such as role-playing and scenarios.

A survey after four hurricanes in Florida in 2004 (no CBRN event) among 53 participants suggests that the training is useful in enhancing knowledge and skills related to traumatic stress reactions and trauma interventions. The training also increased confidence among responders. They applied some of the acquired skills after the hurricanes.

In this scenario, injuries, deaths and destruction to properties were minimal and social support systems stayed intact. Therefore the impact on mental health was moderate to minimal. Components from best practice guidelines on early mental health interventions were applied in the context of the scenario. Recommendations depend on the time phase: Three phases were distinguished: Initial needs (1-3 days), intermediate responses (3 days-3 weeks) and longer term interventions. Besides provision for basic needs, community level programmes were recommended to reduce stress, enhance social support and provide reassurance about future risk. Identifying those at risk for severe impairments is important. Critical interventions in this scenario focused on need assessment, risk communication (leaders who gave consistent messages avoided panic) and targeted interventions fostering natural resilience and support.

This review provides guidance on communicating with the public.

What to say?

- Consider the existing understandings and "mental models" of the public and tailor messages accordingly to correct serious misunderstandings and resonate with current conceptions.

- Before a CBRN event: Find a naturally occurring moment that people become perceptive to information on CBRN attacks (not too early because occurrence and consequences for the public are too uncertain, and not too late so people will not feel unsafe unnecessarily). Give information that is likely to contribute to the possibility of people to protect themselves and others
War with CBRN agents

Combination: CBRN events and general terrorism and war, such as World War I and 2, Gulf War, Iraqi war, US. Anthrax Attacks, Tolyo Sarin Attacks, flu vain supply and military exercises and training

Military psychologists, community leaders
CBRN weapons

Combination: CBRN events, war, pandemics and general disasters/terrorism, such as Hiroshima and Nagasaki bombings, Three Mile Island, Chernobyl disaster, US Anthrax Attacks, World War I and Gulf War, plaque, SARS pandemic, and 9/11 Authorities, health care providers

\section{Bioterrorism}

Public health practitioners, healthcare providers. mental health professionals

Chemical, biological and radiological attacks Scenario of a bomb and Anthrax attack near the Pentagon in the U.S.

Mental health professionals, governmental agencies, first responders

CBRN terrorism

Combination: CBRN events, specifically U.S. Anthrax attacks, London polonium-210 incident, hypothetical scenario's

Communicators 
Reference

(Intervention category ${ }^{\mathrm{a}}$; overall quality of design

Intervention

Event knowledge originated from

Recommendations directed at

- After a CBRN event: Explain how recommended actions work and how we know they are effective. Exposed people need information on the likelihood of exposure (this is a determinant of levels of anxiety and adherence to medication). To prevent low
risk patients seeking medical treatment, communicators should focus on explaining objective signs of exposure (e.g. location or risk patients seeking medical treatment, communicators should focus on explaining objective signs of exposure (e.g. location or
fever) rather than subjective. Information about medication (where they have been tested, when and why required, how well fever) rather than subjective. Inform

they work) may
How to say it?

- Trust determines if messages will be attended to or have the desired effect.

- Ensure that consistent messages are given by representatives from multiple organisations.

- Include representatives and community leaders from different sections of society and in multiple languages.

- Demonstrate that responders are motivated solely by the well-being of those affected, that they are competent and that they are being open and honest. This might even reduce the negative impact of inconsistencies between official messages and media reporting.

Scharoun and Dziegielewski (2010)

$(1,2$; summary of guidelines, weak

commendations from governmental agencies on hospital preparedness and planning to prevent further medical and

Psychological problems are summarised:

Prevent the health infrastructure from getting overwhelmed;

- Detect symptoms of contamination in an early stage (delineating it from common flu);

- Promptly identify the nature of the agents working together with laboratories;

- Initiate a quick response to prevent disease and take decontamination measures:

- Prepare strategies to communicate with experts and the community.

Additionally, the article provides a quick list of questions that help emergency departments assess their level of preparedness. - A nation's preparation for terrorist attacks must include not only physical response mechanisms (medical care and emergency services), but also psychological measures (risk communication and targeted information).

- Effective risk communication could mitigate the adverse behavioural reactions that could undermine a nation's response.

- Give specific advice and instructions on evacuations plans, quarantine, and vaccination strategies.

- Increase the public understanding of CBRN terrorism to promote desired behavioural responses.

Risk communication: provide information on what happened, the reason for intervention and the type of action to be taken. It is essential to build trust between authorities and the public.

(1; unsystematic literature review, weak)

Tinker and Vaughan (2004)

(1; unsystematic literature review and expert

opinion (semi-structured interviews with experts)

weak)

Ursano et al. (2002)

$(1,2,3,4$; expert opinion (summary of 200 conference "Planning for biological events. Responses to terrorism and infectious disease outbreaks"), weak)

Ursano et al. (2002)

$(1,2,3,4$; expert opinion (summary of 2001 conference "Planning for biological events. Respons to terrorism and infectious disease outbreaks"), weak)
An extensive list of recommendations for risk communication is categorised into five main recommendations: - Adopt a strong proactive strategy for risk communication;

- Build public trust and confidence in risk management soon after a suspected or confirmed act of bioterrorism has occurred; - Integrate public risk perspectives into communication planning and preparedness;

- Update and improve risk communication training procedures and preparedness to address the unique challenges by dynamic and evolving risk situations;

-Strengthen risk communications and public health capabilities for rapid responding in the event of an act of bioterrorism. Policy needs: health practice; sustained funding for preventive services and healthcare facilities is necessary.

- Government and private enterprise must form partnerships to address psychosocial consequences of bioterrorist attacks as they affect the continuity of enterprise and productivity at work.

- Roles and responsibilities for mental health- and behavioural response consequence management need to be delineated at al governmental levels.

- There is a need for a national information policy and local implementation plan developed in coordination with representatives of actors at other levels.

- Funding decisions should reflect the critical role of mental health in assuring the continuity of society and an adequate strategy to anticipate psychosocial consequences. The goal of terrorism is the degradation and destruction of the nation's social capital morale, safety and productivity. The continuity of an effective social and community organisation must be given high priority. The mintenance of econic viality is critical as sever economic downturns have been associoted with increased rates of psychiatric illness and suicide.

Public and private business pol

ess policies should be developed to facilitate a rapid recovery in the workplace. Buildings remain intact, but employees may fear returning to them resulting in increased rates of absenteeism and sick leave.

lth interventions should be conceived, developed, and funded in a community support context. For example, the provision of instrumental support (e.g. assistance in finding childcare or alternative travel arrangements) is an important opportunity to sustain resilience.
- Public health infrastructure must be developed or improved at all governmental levels by implementing standards for public
Bioterrorism

(

terrorism

Public health system

Terrorism

Combination: CBRN events and general disasters/ terrorism, specifically Tokyo Sarin attacks, 9/11, U.S Anthrax attacks, London bombings, World War Authorities

Terrorism with radiological dispersion devices Combination: radiological accidents/disasters such as Chernobyl disaster, Goiania Brazil, radiological accident in Istanbul

Authorities

Bioterrorism

Combination: CBRN events and general disasters/

terrorism, such as $9 / 11$

Crisis managers and public health authorities

Bioterrorism

Combination: CBRN and general disasters/terrorism studies and pandemics

Public health authorities, mental health professionals, governmental authorities, media 
- Policies must reflect the medical infrastructure, logistical capacities and personnel availability (e.g. a critical shortage of nurses; the capacity to increase beds,). These matters will determine the medical community's ability to respond.

- Policies must address the psychosocial consequences of instituting quarantine, distributing limited resources, mandatory treatment and the use of investigational drugs.

- The effects of foot and mouth disease demonstrate the important role of mental health programmes for veterinarians, farmers, and ranchers where economic and emotional losses result from bioterrorist

- After an attack there will be tensions between the goals of the scientific world and the political world. Coordination between health care, political offices, and public affairs is needed in an ongoing programme.

Mental health- and behavioural planning

- Public officials should anticipate community beliefs in conspiracy theories; scapegoating, paranoia and stigmatisation are ex pected reactions to a terrorist attack.

- Rapid, accurate tests to diagnose illness are significant ways to diminish anxiety.

- The significant damage to the economy will be followed by a second surge of mental health consequences affecting a much broader spectrum of society.

- Guidelines should be developed that address the psychosocial consequences of quarantine.

- Mental health acute surge capacity and ongoing service resources must be evaluated. Some people suffer from psychiatric disease as support systems are lost and stressors increase. Preplanned community interventions must be available for high-risk groups such as children and the elderly.

- Strategies are needed to diminish terror and mobilise positive action in order to promote resiliency and recovery.

- Multidisciplinary training and education programmes are needed, based on evidence-based practices that span the continuum from early crisis counselling to longer-term care for people with psychiatric disorders.

- The mental health community should determine how existing hotline models can be adapted for effective interventions with an anxious public.

ecal institutions and help groups can be vehicles for fostering social cohesion and decrease fear

- Methods of delivering mental health care that minimise requirements for logistical support (e.g. video tele conferencing, online therapy) must be developed as this can be particularly useful in case of an attack with a contagious organism.

- Plans should include contingencies for providing care in circumstances without electrical power or technology.

- Mental health interventions should include broadly conceived individual and group interventions and policies for improving function, fostering resilience and providing hope. The design of memorial services and how to return workers to an anthraxexposed workplace are examples.

- While panic is rarely seen, prior planning, education, and realistic training reduce the risk of panic amongst professional groups. - The mental health community should work closely with the clergy, who are an integral part of the healthcare disaster response teams.

Communication programmes:

- Physicians require education and preparation on working with the media. Comments must be limited to their professional expertise.

Communications with the public must be bi-directional.

- The mental health community must ensure that journalists have ready access to recognised experts. Journalist and public health officials must work together to ensure accuracy of information.

- The influenza and chickenpox seasons offer an opportunity for the medical community to assist the public in self-triage and to establish workable messages that are effective for various populations with fears of infection and contagion.

-Efforts must be made to develop "simple" health-related slogans that can be useful to the public in preparation.

- Journalists are at high risk for psychological trauma. Efforts should be made to promote resiliency and facilitate their ability to report objectively and accurately.

- Multiple and often not considered information vehicles are important for information distribution before and after an attack (e.g. popular TV shows, reading tabloids, the internet).

- Journalists and physicians should continuously develop strategies for controlling false rumours, and developing educational messages.

- Educate journalists on the issues of CBRN threats. "Hands on" training is welcome. For example, wearing protective gear worn by first responders or working in a laboratory to see how Anthrax testing works.

- Public information strategies should be built around the journalistic formula: "Who, what, when, where, why, and how?"

- Provide a central website that is updated frequently and offers links to information about bioterrorism health issues.

- Provide funding to adapt information developed nationally for other levels.

- Governmental authorities need to identify local and credible experts and link them with media programmes.

- Inform public and business leaders about the right language to avoid stigmatisation and improper triage.

- Inform public and busion and training:

-Educate leadership at all levels about the psychological and behavioural implications of crisis management and issues in relation to bioterrorism. Create awareness.

Education and training of primary care providers on psychological and behavioural responses is a priority. Traumatic events and chronic stress can have a direct effect on mental health and on medical problems (e.g. diabetes, heart disease). 
Reference

(Intervention categorya; overall quality of design)

Intervention

- Educate leaders about the challenges of bioterrorism for the current mental health system and its lack of surge capacity, particularly about the long-term in relation to the community.

- Educate public leaders, the media, and entertainers about the expected problems produced by stigmatisation and conspiratorial theories in the wake of catastrophic events.

Decision support (data acquisition for health surveillance and programmes development):

- Make mental health surveillance a standard part of post-bioterrorism responses. Provide "real time" assessments of community perceptions, fears and symptoms, monitor changing mental health needs, and adjust resources accordingly. Use a variety of channels (telephone, internet, .

stributing to people's sense of safety and factors promoting altruism under difficult circumstances, eople to cooperate with quarantine?

Perform epidemiological studies of mental health responses to terrorism and the effect of ongoing terrorist threats on menta health and behavioural service needs.

Evaluate mental health interventions in order to plan for subsequent attacks.

- Do research to identify unrecognised high-risk populations (such as bereaved parents of adult children) in order to develop specialised intervention programmes.

- Research should delineate valid community wide measures of mental health (such as the rates of prescriptions for psychotropic medications, alcohol use, school and work absences) that can be incorporated into surveillance programmes.

- Develop templates at national level for collecting mental health surveillance data and developing useful databases. Adapt these templates to intermediate and local levels.

- Develop a detailed taxonomy of disasters including bioterrorism. Identify common and discriminating elements associated with various events. Information on contextual issues is important.

- Lessons learned from earlier events e.g. September 11th and the anthrax attacks) should be incorporated into response plans. - Organise support concerning the course of neurobehavioral change and the impact of psychosocial and psychopharmacological interventions.

Vazquez et al. (2010)

$(1,2,3,4$; unsystematic literature review, weak)

\section{Wessely (2005)}

$(1,2,3,4$; unsystematic literature review, weak)

Establish an organisational traumatic incident management team;
In order to cope with traumatic stress, all organisations involved in preparedness and response should:

- Recommend responder strategies for the handling of traumatic stress (e.g. no alcohol, quick relaxation techniques, avoid isolation, limiting the time watching news, keeping in mind that during stressing times "it is normal not to feel well", etc); - Contemplate the intervention of a "mental health team" in plans:

- Include specific training on stress awareness programmes for managers and stress management for all the staff;

- Promote interactions with professionals from other disciplines such as social workers, sociologists and anthropologists enabling

a more comprehensive approach to the problem;

- Inform and educate the population to look for more adequate individual and organisational responses,

- Establish support programmes to assist families:

- Instruct the public information officer to inform with clearly and updated facts (prevent rumours);

- Promote debriefing reunions as a tool for information and social support.

Short term:

- The first thing people want is practical support, the second thing is to talk (or not to talk) with persons in their own persona network, professionals are low on the list.

- Immediate post trauma counselling of normal people ("debriefing") does not reduce distress or promote resilience.

- Interventions must be practical rather than emotional: give timely and accurate information and promote social support of family and friends. Try not to block mobile telephone networks because people need to find their loved ones.

- Hospitals may get overwhelmed by people seeking (mostly unnecessary) medical help because of anxiety, uncertainty ove perceived symptoms or general concern: preparation is important for instance by stockpiling simple information cards to be perceived symptoms or general concern: preparation is important for instance by stockpiling simple information cards to

Long term:

Rumours and uncertainty on health effects may cause distrust, sap resilience and increase psychosocial problems. This scenario will be easier to manage if

- During the acute crisis authorities are perceived as being open and secure;

- Authorities are responding fairly and do not seem to discriminate between, for instance, poor postal workers or rich staff,

- attempts were made during the acute incident to maintain a register of who was and who was not exposed;

- authorities have a programme of sensible research in place from an early period and not in response to later public/media pressure.
Type of event focused on

Event knowledge originated from

Recommendations directed at

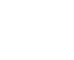

(1) 
Williams and Williams (2010)

(2; guideline, weak)

Wodarski (2004)

$(2,3,4$; unsystematic literature review, weak $)$
Prior training and education are needed to address fears and ensure a positive response. Nurses are less willing to respond to dirty bombs because of concerns about safety of loved ones, potential staffing problems, contamination, lack of information and selfprotection.

To address the information gap between nurses' concerns and the impact of radiological dispersal devices, knowledge should be ncreased on radiological decontamination, self-protection, and their role. Important information is that patients can usually selfdecontaminate and pose no genuine threat to nursing staf

Mental health professionals must be prepared to deal with the following common psychological reactions (cf. Holloway et al., 2002; Plum and Veenema, 2003): (1) horror, anger and/or panic; (2) illogical thinking about microbes and viruses; (3) fear of nvisible agents and/or fear of contagion; (4) attribution of arousal symptoms to infection; (5) anger at terrorists, the governmen or both; (6) scapegoating, loss of faith in social institutions; and (7) paranoia, social isolation and/or demoralisation.

Mental health practitioners will have to be trained in (cf. Holloway et al., 2002; Plum and Veenema, 2003):

- Prevention of group panic;

- Avoiding a "rush" through the grievance process;

- Careful rapid medical evaluation and treatment (to distinguish between hyper arousal, intoxication and infection);

- Avoidance of emotion-based responses;

- Effective coordination regarding potential risk:

- Control of symptoms secondary to hyper arousal (provide reassurance, or medication if necessary);

- Management of anger, fear or both;

Managenent of mistribution of somatic symptoms;

- Provision of respite as required;

Restoration of an effective, useful social role (e.g. as worker at a triage site);

Return to usual sources of social support in the community.

Mental health providers must learn specific skills to provide for effective care giving:

Constructive coping styles;

Normalising thoughts, feelings and behaviours;

- Support for family members

- Reactions to trauma

- Stress-related problems (anxiety, sleeplessness, low motivation)

- Provision of resources (stress reduction, problem-solving, cognitive restructuring, appropriate assertiveness)

- Self-care for professionals

- Giving exact information

For the development of an integrated community disaster preparedness programme, the following activities should be imple-

mented:

- Develop and initiate (electronic) network information dissemination procedures.

- Develop reader friendly brief communications on guidelines for provision of disaster preparedness services.

- Develop brief trainings in stress reduction, cognitive restructuring and strategies for "re-charging batteries".

- Provide community information on empirically based interventions and evaluation of outcomes.

- Provide community information on empirically based interven

Contine pooring

- Execute relevant research studies.

- Execute relevant research studies.

Hold conferences that facilitate various response networks.

Conduct in-service training at hospitals, police stations and mental health facilities on biological, chemical and radiologica disaster preparedness.
Radiological dispersal devices

Combination: CBRN events and general disasters/ terroris

Biological, chemical and radiological assaults Combination: CBRN events and general disasters/ terrorism

Social services and public health professionals 


\section{References}

Alexander D. Principles of emergency planning and management. New York: Oxford University Press; 2002.

Alexander DA, Klein S. Biochemical terrorism: too awful to contemplate, too serious to ignore: subjective literature review. Br J Psychiatry 2003;183:491-7.

American Psychiatric Association. Diagnostic and statistical manual of mental disorders. 5th ed. Arlington: American Psychiatric Publishing; 2013.

Auvinen A, Vahteristo M, Arvela H, Suomela M, Rahola R, Hakama M, et al. Chernobyl fallout and outcome of pregnancy in Finland. Environ Health Perspect 2001:109:179-85.

Becker SM. Addressing the psychosocial and communication challenges posed by radiological/nuclear terrorism: key developments since NCRP report no. 138. Health Phys 2005;89:521-30.

Benedek DM, Holloway HC, Becker SM. Emergency mental health management in bioterrorism events. Emerg Med Clin North Am 2002;20:393-407.

Bertollini R, DiLallo D, Mastroiacovo P, Perucci C. Reduction of births in Italy after the Chernobyl accident. Scand J Work Environ Health 1990;16:96-101.

Bisson JI, Tavakoly B, Witteveen AB, Adjdukovic D, Jehel L, Johansen VJ, et al. TENTS guidelines: development of post-disaster psychosocial care guidelines through a Delphi process. Br J Psychiatry 2010;196:69-74.

Blanchard JC, Haywood Y, Stein BD, Tanielian TL, Stoto M, Lurie N. In their own words: lessons learned from those exposed to anthrax. Am J Public Health 2005;95:489-95.

Bonanno GA, Brewin CR, Kaniasty K, La Greca AM. Weighing the costs of disaster: consequences, risks, and resilience in individuals, families, and communities. Psychol Sci Public Interest 2010;11:1-49.

Bromet EJ. Mental health consequences of the Chernobyl disaster. J Radiol Prot 2012;32: N71-5.

Bromet EJ, Havenaar JM. The long-term mental health impact of the Chernobyl accident. In: Neria Y, Galea S, Norris FH, editors. Mental health and disasters. Cambridge: Cambridge University Press; 2009. p. 441-53.

Considine C, Mitchell B. Chemical, biological and radiological incidents: preparedness and perceptions of emergency nurses. Disasters 2009;33:482-97.

Cowan AE, Ching PL, Clark SJ, Kemper AR. Willingness of private physicians to be involved in smallpox preparedness and response activities. Biosecur Bioterror 2005;3:16-22.

Cwikel JG, Havenaar JM, Bromet EJ. Understanding the psychological and societal response of individuals, groups, authorities, and media to toxic hazards. In: Havenaar JM, Cwikel JG, Bromet EJ, editors. Toxic turmoil: psychological and societal consequences of ecological disasters. New York: Kluwer Academic/Plenum Publishers; 2002. p. 39-65.

DiGiovanni Jr C. The spectrum of human reactions to terrorist attacks with weapons of mass destruction: early management considerations. Prehosp Disaster Med 2003; 18:253-7.

Dodgen D, Norwood AE, Becker SM, Perez JT, Hansen CK. Social, psychological, and behavioral responses to a nuclear detonation in a US city: implications for health care planning and delivery. Disaster Med Public Health Prep 2011;5(Suppl. 64).

Dückers MLA. Five essential principles of post-disaster psychosocial care: looking back and forward with Stevan Hobfoll. Eur J Psychotraumatol 2013:4:21914.

Durodie B. Facing the possibility of bioterrorism. Curr Opin Biotechnol 2004;15:264-8.

Eccles M, Grimshaw J, Campbell M, Ramsay C. Research designs for studies evaluating the effectiveness of change and improvement strategies. Qual Saf Health Care 2003:12:47-52.

Engel CC, Jaffer A, Adkins J, Riddle JR, Gibson R. Can we prevent a second 'Gulf War syndrome'? Population-based healthcare for chronic idiopathic pain and fatigue after war. Adv Psychosom Med 2004;25:102-22.

Engel CC, Hyams KC, Scott K. Managing future Gulf War syndromes: international lessons and new models of care. Philos Trans R Soc Lond B Biol Sci 2006;361:707-20.

Engel CC, Locke S, Reissman DB, DeMartino R, Kutz I, McDonald M, et al. Terrorism, trauma, and mass casualty triage: how might we solve the latest mind-body problem? Biosecur Bioterror 2007;5:155-63.

Fullerton CS, Ursano RJ, Norwood AE. Planning for the psychological effects of bioterrorism. In: Ursano RJ, Norwood AE, Fullerton CS, editors. Bioterrorism: psychological and public health interventions. New York: Cambridge University Press; 2004. p. 2-14.

Grievink L, Van der Velden PG, Stellato RK, Dusseldorp A, Gersons BPR, Kleber RJ, et al. A longitudinal comparative study of the physical and mental health problems of affected residents of the firework disaster Enschede, the Netherlands. Public Health 2007; 121:367-74.

Hall MJ, Norwood AE, Fullerton CS, Ursano RJ. Preparing for bioterrorism at the state level: report of an informal survey. Am J Orthopsychiatry 2002;72:486-91.

Hall MJ, Norwood AE, Fullerton CS, Gifford R, Ursano RJ. The psychological burden of bioterrorism. J Aggress Maltreat Trauma 2004;9:293-304.

Havenaar JM, Van den Brink W. Psychological factors affecting health after toxicological disasters. Clin Psychol Rev 1997;17:359-74.

Havenaar JM, Van Den Brink W, Van Den Bout J, Kasyanenko AP, Poelijoe NW, Wohlfarth $\mathrm{T}$, et al. Mental health problems in the Gomel region (Belarus): an analysis of risk factors in an area affected by the Chernobyl disaster. Psychol Med 1996;26:845-55.

Hick JL, Weinstock DM, Coleman CN, Hanfling D, Cantrill S, Redlener I, et al. Health care system planning for and response to a nuclear detonation. Disaster Med Public Health Prep 2011;5(Suppl. 88)

Hobfoll SE, Watson P, Bell CC, Bryant RA, Brymer MJ, Friedman MJ, et al. Five essential elements of immediate and mid-term mass trauma intervention: empirical evidence. Psychiatry 2007;70:283-315.

Holloway HC, Norwood AE, Fullerton CS, Engel CC, Ursano RJ. The threat of biological weapons: prophylaxis and mitigation of psychological and social consequences. J Am Med Assoc 2002;278:425-7.

Hyams KC, Murphy FM, Wessely S. Responding to chemical, biological, or nuclear terrorism: the indirect and long-term health effects may present the greatest challenge. J Health Polit Policy Law 2002;27:273-91.
Impact Multidisciplinaire richtlijn vroegtijdige psychosociale interventies na rampen, terrorisme en andere schokkende gebeurtenissen (Multidisciplinairy guidelines early psychosocial interventions after disasters, terrorism and other shocking events) Utrecht: Trimbos Institute; 2007.

International Federation of the Red Cross and Red Crescent Societies. World disaster report. Focus on information in disasters. Geneva: IFRC; 2005.

Johnson A, Howe JL, McBride MR, Palmisano BR, Perweiler EA, Roush RE, et al Bioterrorism and Emergency Preparedness in Aging (BTEPA): HRSA-funded GEC collaboration for curricula and training. Gerontol Geriatr Educ 2006;26: 63-86.

Kikuchi S, Kikuchi T. The medical association activity and pediatric care after the earthquake disaster in Fukushima. Keio J Med 2012:61:23-7.

Knudsen L. Legally-induced abortions in Denmark after Chernobyl. Biomed Pharmacothe $1991 ; 45: 229-32$.

Knudson GB. Nuclear, biological, and chemical training in the U.S. army reserves: mitigating psychological consequences of weapons of mass destruction. Mil Med 2001 166(Suppl. 5).

Lemyre L, Clement M, Corneil W, Craig L, Boutette P, Tyshenko M, et al. A psychosocial risk assessment and management framework to enhance response to CBRN terrorism threats and attacks. Biosecur Bioterror 2005;3:316-30.

Lemyre L, Corneil W, Johnson C, Boutette P. Psychosocial considerations about children and radiological events. Radiat Prot Dosimetry 2010a;142:70-6.

Lemyre L, Johnson C, Corneil W. Psychosocial considerations for mass decontamination. Radiat Prot Dosimetry 2010b;142:17-23.

Markel G, Krivoy A, Rotman E, Schein O, Shrot S, Brosh-Nissimov T, et al. Medical management of toxicological mass casualty events. Isr Med Assoc J 2008;10:761-6.

Neria Y, Nandi A, Galea S. Post-traumatic stress disorder following disasters: a systematic review. Psychol Med 2008;38:467-80.

Neria Y, Galea S, Norris FH. Mental health and disasters. Cambridge: Cambridge University Press; 2009.

Norris FH, Friedman MJ, Watson PJ. 60,000 disaster victims speak: part II. Summary and implications of the disaster mental health research. Psychiatry 2002a;65:240-60.

Norris FH, Friedman MJ, Watson PJ, Byrne CM, Diaz E, Kaniasty K. 60,000 disaster victims speak: part I. An empirical review of the empirical literature, 1981-2001. Psychiatry 2002b;65:207-39.

Noy S. Minimizing casualties in biological and chemical threats (war and terrorism): the importance of information to the public in a prevention program. Prehosp Disaster Med 2004;19:29-36

NSW Institute of Psychiatry and Centre for Mental Health. Disaster Mental Health Response Handbook. North Sydney: New South Wales Health; 2000.

O'Boyle C, Robertson C, Secor-Turner M. Public health emergencies: nurses' recommendations for effective actions. AAOHN J 2006;54:347-53.

Ohbu S, Yamashina A, Takasu N, Yamaguchi T, Murai T, Nakano K, et al. Sarin poisoning on Tokyo subway. South Med J 1997;90:587-93.

Oordt MS. The psychological effects of weapons of mass destruction. In: Kennedy $\mathrm{CH}$ Zillmer EA, editors. Military psychology: clinical and operational applications. New York: Guilford Press; 2006. p. 295-309.

Pastel RH, Ritchie EC. Mitigation of psychological effects of weapons of mass destruction. In: Ritchie EC, Watson PJ, Friedman MJ, editors. Interventions following mass violence and disasters: strategies for mental health practice. New York: Guilford Press; 2006. p. 300-18.

Petterson JS. Perception vs. reality of radiological impact: the Goiania model. Nucl News 1988;31:84-90

Plum KC, Veenema TG. Management of psychological effects. In: Veenema TG, editor Disaster nursing and emergency preparedness for chemical, biological and radiological terrorism and other hazards. New York: Springer; 2003.

Reid WM, Ruzycki S, Haney ML, Brown LM, Baggerly J, Mescia N, et al. Disaster menta health training in Florida and the response to the 2004 hurricanes. J Public Health Manag Pract 2005:S57-62. [Suppl.]

Ritchie EC, Friedman M, Watson P, Ursano R, Wessely S, Flynn B. Mass violence and early mental health intervention: a proposed application of best practice guidelines to chemical, biological, and radiological attacks. Mil Med 2004; 169:575-9.

Rokach A, Cohen R, Shapira N, Einav S, Mandibura A, Bar-Dayan Y. Preparedness for anthrax attack: the effect of knowledge on the willingness to treat patients. Disasters 2010;34:637-43.

Rubin GJ, Chowdhury AK, Amlôt R. How to communicate with the public about chemical, biological, radiological, or nuclear terrorism: a systematic review of the literature. Biosecur Bioterror 2012;10:383-95.

Scharoun K, Dziegielewski SF. Bioterrorism and the emergency room: planning for the unexpected. Stress Trauma Crisis Int J 2010;7:135-50.

Seligman MEP. The effectiveness of psychotherapy. The consumer reports study. Am Psychol 1995;50:965-74

Sheppard B, Rubin GJ, Wardman JK, Wessely S. Terrorism and dispelling the myth of a panic prone public. J Public Health Policy 2006;27:219-45.

Smith EC, Burkle Jr FM, Archer F. Fear, familiarity, and the perception of risk: a quantitative analysis of disaster-specific concerns of paramedics. Disaster Med Public Health Prep 2011:5:46-53.

Smithson A, Levy L-A. Rethinking the lessons of Tokyo. In: Smithson A, Levy L-A, editors. Ataxia, the chemical and biological terrorism threat and the U.S. response, report no. 35. Washington DC: Henry L. Stimson Center; 1999. p. 71-111.

Sohier A, Hardeman F. Radiological dispersion devices: are we prepared? J Environ Radioact 2006;85:171-81.

Te Brake H, Dückers M. Early psychosocial interventions after disasters, terrorism and other shocking events: is there a gap between norms and practice in Europe? Eur Psychotraumatol 2013;4. http://dx.doi.org/10.3402/ejpt.v4i0.19093. 
Te Brake H, Dückers M, De Vries M, Van Duin D, Rooze M, Spreeuwenberg C. Early psychosocial interventions after disasters, terrorism, and other shocking events: guideline development. Nurs Health Sci 2009;11:336-43.

Tinker TL, Vaughan E. Communicating the risks of bioterrorism. In: Ursano RJ, Norwood AE, Fullerton CS, editors. Bioterrorism: psychological and public health interventions. New York: Cambridge University Press; 2004. p. 308-29.

Ursano RJ, Fullerton CS, Norwood AE. Responding to bioterrorism: individual and community needs. Bethesday MD: Uniformed Services University of the Health Sciences; 2002.

Vazquez M, Jordan O, Kuper E, Hernandez D, Galmarini M, Ferraro A. Management of acute traumatic stress in nuclear and radiological emergencies. Health Phys 2010; 98:795-8.

Weisaeth L, Tonnessen A. Responses of individuals and groups to consequences of technological disasters and radiation exposure. In: Norwood AE, editor. Terrorism and disaster: individual and community mental health interventions. New York: Cambridge University Press; 2003. p. 209-35.
Wessely S. Don't panic! Short and long term psychological reactions to the new terrorism: the role of information and the authorities. J Ment Health 2005;14:1-6.

Williams $\mathrm{G}$, Williams E. A nursing guide to surviving a radiological dispersal device. $\mathrm{Br} \mathrm{J}$ Nurs 2010;19:24-7.

Witteveen AB, Bisson JI, Ajdukovic D, Arnberg FK, Bergh Johannesson K, Bolding HB, et al. Post-disaster psychosocial services across Europe: the TENTS project. Soc Sci Med 2012;75:1708-14.

Wodarski JS. Preparing social services and public services professionals for meaningful roles in disaster services. Stress Trauma Crisis Int J 2004;7:209-22.

World Health Organization (WHO) Guidelines of the management of conditions specifically related to stress. Geneva: WHO; 2013.

World Trade Organization (WTO) World trade report 2012. Trade and public policies. A closer look at non-tariff measures in the 21st century. Geneva: WTO; 2012.

Wynia MK, Gostin LO. Ethical challenges in preparing for bioterrorism: barriers within the health care system. Am J Public Health 2004;94:1096-102. 